\title{
Effectiveness of music therapy: a summary of systematic reviews based on randomized controlled trials of music interventions
}

REVIEW

\author{
Hiroharu Kamioka' \\ Kiichiro Tsutani ${ }^{2}$ \\ Minoru Yamada ${ }^{3}$ \\ Hyuntae Park ${ }^{4}$ \\ Hiroyasu Okuizumi ${ }^{5}$ \\ Koki Tsuruoka ${ }^{6}$ \\ Takuya Honda ${ }^{7}$ \\ Shinpei Okada ${ }^{8}$ \\ Sang-Jun Park ${ }^{8}$ \\ Jun Kitayuguchi ${ }^{9}$ \\ Takafumi Abe ${ }^{9}$ \\ Shuichi Handa ${ }^{5}$ \\ Takuya Oshio ${ }^{10}$ \\ Yoshiteru Mutoh"I
}

'Faculty of Regional Environment Science, Tokyo University of Agriculture, Tokyo, Japan; ${ }^{2}$ Department of Drug Policy and Management, Graduate School of Pharmaceutical Sciences, The University of Tokyo, Tokyo, Japan; ${ }^{3}$ Kyoto University Graduate School Research, Kyoto, Japan; ${ }^{4}$ Department of Functioning Activation, National Center for Geriatrics and

Gerontology, Aichi, Japan; ${ }^{5}$ Mimaki Onsen (Spa) Clinic, Tomi, Nagano, Japan; ${ }^{6}$ Graduate School of Social Services, Japan College of Social Work, Tokyo, Japan; ${ }^{7} J a p a n e s e$ Society for the Promotion of Science, Tokyo, Japan; ${ }^{8}$ Physical Education and Medicine Research Foundation, Tomi, Nagano, Japan; 'Physical Education and Medicine Research Center Unnan, Shimane, Japan; ${ }^{10}$ Social Welfare Service Corporation CAREPORT MIMAKI, Tomi, Nagano, Japan; "The Research Institute of Nippon Sport Science University, Tokyo, Japan

Correspondence: Hiroharu Kamioka Faculty of Regional Environment Science, Tokyo University of Agriculture,

I-I-I Sakuragaoka, Setagaya-ku,

Tokyo 156-8502, Japan

$\mathrm{Tel} / \mathrm{fax}+8 \mathrm{I} 354772587$

Email hIkamiok@nodai.ac.jp
This article was published in the following Dove Press journal:

Patient Preference and Adherence

16 May 2014

Number of times this article has been viewed

Objective: The objective of this review was to summarize evidence for the effectiveness of music therapy (MT) and to assess the quality of systematic reviews (SRs) based on randomized controlled trials (RCTs).

Study design: An SR of SRs based on RCTs.

Methods: Studies were eligible if they were RCTs. Studies included were those with at least one treatment group in which MT was applied. We searched the following databases from 1995 to October 1, 2012: MEDLINE via PubMed, CINAHL (Cumulative Index of Nursing and Allied Health Literature), Web of Science, Global Health Library, and Ichushi-Web. We also searched all Cochrane Database and Campbell Systematic Reviews up to October 1, 2012. Based on the International Classification of Diseases, 10th revision, we identified a disease targeted for each article.

Results: Twenty-one studies met all inclusion criteria. This study included 16 Cochrane reviews. As a whole, the quality of the articles was very good. Eight studies were about "Mental and behavioural disorders (F00-99)"; there were two studies on "Diseases of the nervous system (G00-99)" and "Diseases of the respiratory system (J00-99)"; and there was one study each for "Endocrine, nutritional and metabolic diseases (E00-90)", "Diseases of the circulatory system (I00-99)", and "Pregnancy, childbirth and the puerperium (O60)". MT treatment improved the following: global and social functioning in schizophrenia and/or serious mental disorders, gait and related activities in Parkinson's disease, depressive symptoms, and sleep quality.

Conclusion: This comprehensive summary of SRs demonstrated that MT treatment improved the following: global and social functioning in schizophrenia and/or serious mental disorders, gait and related activities in Parkinson's disease, depressive symptoms, and sleep quality. MT may have the potential for improving other diseases, but there is not enough evidence at present. Most importantly, no specific adverse effect or harmful phenomenon occurred in any of the studies, and MT was well tolerated by almost all patients.

Keywords: ICD-10, schizophrenia, mental disorders, Parkinson's disease, depression, sleep

\section{Article focus}

Although many studies have reported the effects of music therapy (MT), there is no review of systematic reviews (SRs) based on randomized controlled trials (RCTs).

\section{Key messages}

The key messages of this paper are as follows.

1. This is the first SR of SRs of the effectiveness of cure based on music interventions in studies with RCT designs. 
2. Our study is unique because it summarizes the evidence for each target disease according to the International Classification of Diseases, revision 10 (ICD-10).

3. We propose the future research agenda for studies on the treatment effect of MT.

\section{Strength and limitation of this study}

The strengths of this study are as follows: 1) the methods and implementation registered high on the PROSPERO database; 2) it was a comprehensive search strategy across multiple databases with no data restrictions; and 3) there were high agreement levels for quality assessment of articles.

This study has three limitations. Firstly, some selection criteria were common across studies; however, the bias remained due to differences in eligibility for participation in each original RCT. Secondly, publication bias was a limitation. Lastly, since this review focused on summarizing the effects of MT for each disease, we did not describe all details on quality and quantity, such as type of MT, frequency of MT, and time on MT.

\section{Introduction}

MT is widely utilized for treatment of and assistance in various diseases. In one literature review, the authors found seven case reports/series and seven studies on MT for multiple sclerosis patients. The results of these studies as well as the case reports demonstrated patients' improvements in the domains of self-acceptance, anxiety, and depression. ${ }^{1}$ Another review examined the overall efficacy of MT in children and adolescents with psychopathology, and examined how the size of the effect of MT is influenced by the type of pathology, the subject's age, the MT approach, and the type of outcome. ${ }^{2}$ The analysis revealed that MT had a medium to large positive effect (effect size $=0.61$ ) on clinically relevant outcomes that was statistically highly significant $(P<0.001)$ and statistically homogeneous. A more recent SR assessed the effects of musical elements in the treatment of individuals with acquired neurological disorder. ${ }^{3}$ The results showed that mechanisms of recovery remained unclear: two of the three studies that examined mechanisms of recovery via neuro-imaging techniques supported the role of the right hemisphere, but reports were contradictory, and exact mechanisms of recovery remained indefinable. An interesting metaanalysis described results that justified strong consideration for the inclusion of neonatal intensive care unit (NICU) MT protocols in best practice standards for NICU treatment of preterm infants: examples of these therapies were listening to music for pacification, music reinforcement of sucking/ feeding ability, and music as a basis for pacification during multilayered, multimodal stimulation. ${ }^{4}$

Examining the curative effects of MT has unique challenges. A review article by Nilsson ${ }^{5}$ described how nurses face many challenges as they care for the needs of hospitalized patients, and that they often have to prioritize physical care over the patient's emotional, spiritual, and psychological needs. In clinical practice, music intervention can be a tool to support these needs by creating an environment that stimulates and maintains relaxation, wellbeing, and comfort. Furthermore, the Nilsson article ${ }^{5}$ presented a concrete recommendation for music interventions in clinical practice, such as "slow and flowing music, approximately 60 to 80 beats per minute", "nonlyrical", "maximum volume level at $60 \mathrm{~dB}$ ", "patient's own choice, with guidance", "suitable equipment chosen for the specific situation", "a minimum duration of 30 minutes in length", and "measurement, follow up, and documentation of the effects". In addition, MT has been variably applied as both a primary and accessory treatment for persons with addictions to alcohol, tobacco, and other drugs of abuse. However, an $\mathrm{SR}^{6}$ described that no consensus exists regarding the efficacy of MT as treatment for patients with addictions.

On the other hand, music may be considered an adjunctive therapy in clinical situations. Music is effective in reducing anxiety and pain in children undergoing medical and dental procedures. ${ }^{7}$ A meta-analysis confirmed that patients listening to music during colonoscopy, which is now the recommended method for screening colon cancer, was an effective method for reducing procedure time, anxiety, and the amount of sedation. More importantly, no harmful effects were observed for all the target studies. ${ }^{8}$ The usual practice following a cervical cancer abnormal cervical smear is to perform a colposcopy. However, women experience high levels of anxiety and negative emotional responses at all stages of cervical screening. An SR of RCTs evaluated interventions designed to reduce anxiety levels during colposcopic examination. Psychosexual dysfunction (ie, anxiety) was reduced by playing music during colposcopy. ${ }^{9}$

The definition of musical intervention is complex, but the literature describes two broad categories of music interventions: music medicine and MT. ${ }^{10}$ Music medicine is the use of passive listening (usually involving prerecorded music) as implemented by medical personnel. In music medicine studies, the subject's preference for the music used may be considered by having him or her select from a variety of tapes. Alternately, some studies use predefined 
music stimuli that do not take the subject's preferences into account. Furthermore, there is generally no attempt by the researcher to form a therapeutic relationship with the subject, and there is no process involved in the music treatment. In essence, music medicine studies usually allow one to assess the effects of music alone as a therapeutic intervention. In contrast, MT interventions most often involve a relationship between the therapist and the subject, the use of live music (performed or created by the therapist and/or patient), and a process that includes assessment, treatment, and evaluation. Patient preference for the music is usually a consideration in MT studies.

We were interested in evaluating the curative effect of MT according to diseases because many of the primary studies and review articles of much MT have reported results in this way. In particular, we wanted to focus on all cure and rehabilitation effects using the ICD-10. It is well known in research design that evidence grading is highest for an SR with meta-analysis of RCTs. Although many studies have reported the effects of MT, there is no review of SRs based on RCTs. The objective of this review was to summarize evidence for the effectiveness of MT and to assess the quality of SRs based on RCTs of these therapies.

\section{Methods}

\section{Criteria for considering studies included in this review \\ Types of studies}

Studies were eligible if they were SRs (with or without a meta-analysis) based on RCTs.

\section{Types of participants}

There was no restriction on patients.

\section{Types of intervention and language}

Studies included were those with at least one treatment group in which MT was applied. The definition of MT is complex, but in this study, any kind of MT (not only music appreciation but also musical instrument performance and singing, for example) was permitted and defined as an intervention. Studies had to include information on the use of medication, alternative therapies, and lifestyle changes, and these had to be comparable among groups. There was no restriction on the basis of language.

\section{Types of outcome measures}

We focused on all cure and rehabilitation effects using the ICD-10.

\section{Search methods for studies identification}

\section{Bibliographic database}

We searched the following databases from 1995 to October 1, 2012: MEDLINE via PubMed, Cumulative Index of Nursing and Allied Health Literature (CINAHL), Web of Science, Ichushi Web (in Japanese), the Global Health Library (GHL), and the Western Pacific Region Index Medicus (WPRIM). The International Committee of Medical Journal Editors (ICMJE) recommended uniform requirements for manuscripts submitted to biomedical journals in 1993. We selected articles published (that included a protocol) since 1995, because it appeared that the ICMJE recommendation had been adopted by the relevant researchers and had strengthened the quality of the reports.

We also searched the Cochrane Database of Systematic Reviews (Cochrane Reviews), the Database of Abstracts of Reviews of Effects (Other Reviews), the Cochrane Central Register of Controlled Trials (Clinical Trials or CENTRAL), the Cochrane Methodology Register (Methods Studies), the Health Technology Assessment Database (Technology Assessments), the NHS Economic Evaluation Database (Economic Evaluations), About The Cochrane Collaboration databases (Cochrane Groups), the Campbell Systematic Reviews (the Campbell Collaboration), and the All Cochrane, up to October 1, 2012.

All searches were performed by two specific searchers (hospital librarians) who were qualified in medical information handling, and who were experienced in searches of clinical trials.

\section{Search strategies}

The special search strategies contained the elements and terms for MEDLINE, CINAHL, Web of Science, Ichushi Web, GHL, WPRIM, and All Cochrane databases (Figure 1 and Table 1). Only keywords about intervention were used for the searches. First, titles and abstracts of identified published articles were reviewed in order to determine the relevance of the articles. Next, references in relevant studies and identified SRs were screened.

\section{Registry checking}

We searched the International Clinical Trials Registry Platform (ICTRP), Clinical Trials.gov, and the University Hospital Medical Information Network - Clinical Trials Registry (UMIN-CTR), up to October 1, 2012.

ICTRP in the WHO Registry Network meet specific criteria for content, quality and validity, accessibility, unique 


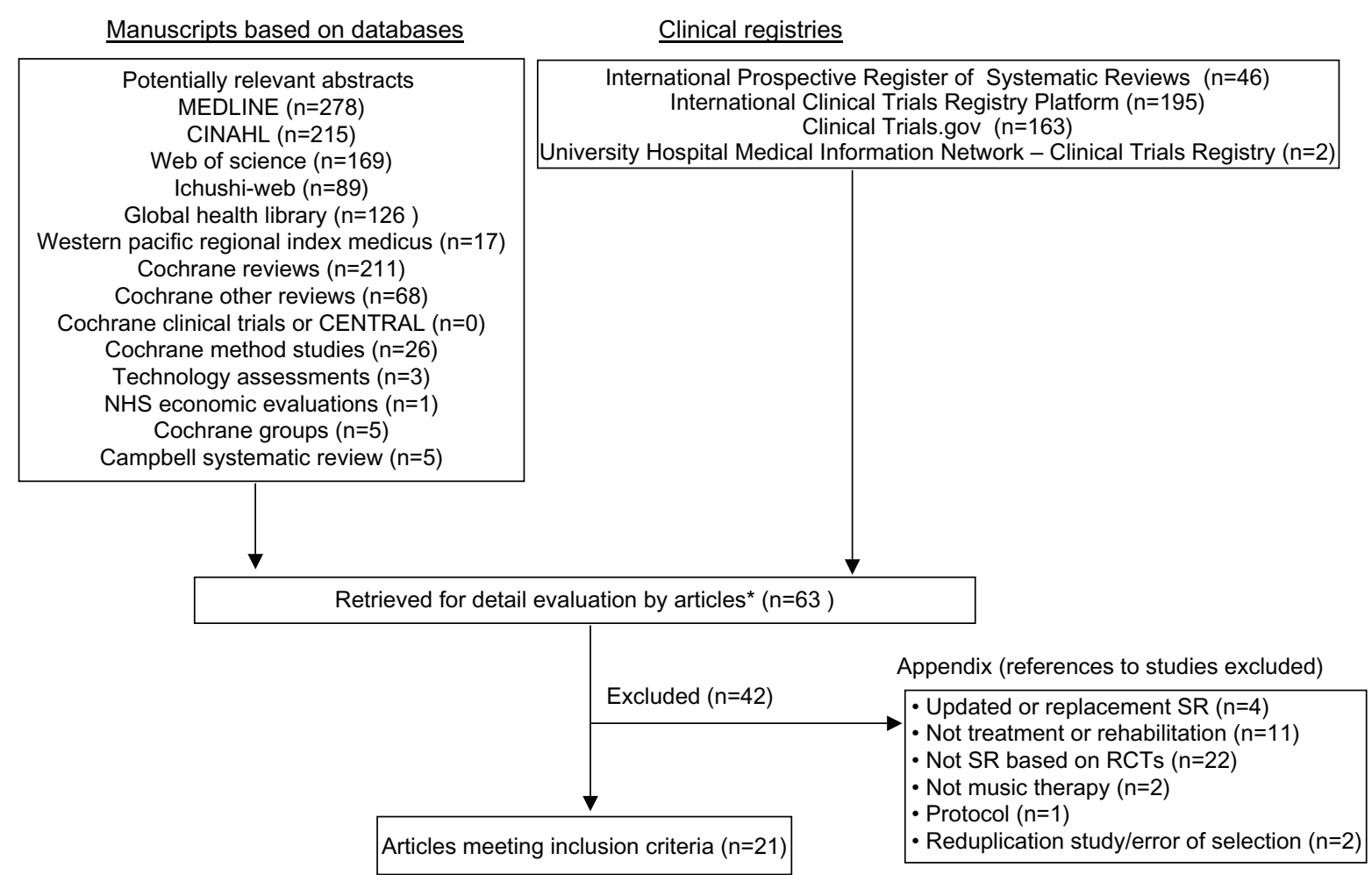

Figure I Flowchart of trial process

Note: *Reduplication.

Abbreviations: CINAHL, Cumulative Index of Nursing and Allied Health Literature; CENTRAL, Cochrane Central Register of Controlled Trials; RCT, randomized controlled trial; SR, systematic review.

identification, technical capacity, and administration. Primary registries meet the requirements of the ICMJE. Clinical Trials.gov is a registry of federally and privately supported clinical trials conducted in the US and around the world. UMIN-CTR is a registry of clinical trials conducted in Japan and around the world.

\section{Handsearching and reference checking}

We handsearched abstracts published on MT in relevant journals in Japan. We checked the references of included studies for further relevant literature.

\section{Review methods}

\section{Selection of trials}

To make the final selection of studies for the review, all criteria were applied independently by four authors (ie, TH, JK, SJP, and TA) to the full text of articles that had passed the first eligibility screening (Figure 1). Disagreements and uncertainties were resolved by discussion with other authors (ie, HK, KT, and YM).

Studies were selected when 1) the design was an SR based on RCTs and 2) one of the interventions was a form of MT. Protocols without results were excluded, and we included only completed studies. Cure and rehabilitation effects were used as a primary outcome measure. Trials that were excluded are presented with reasons for exclusion (Table S1).

\section{Quality assessment of included studies}

To ensure that variation was not caused by systematic errors in the study design or execution, eleven review authors (HP, MY, HO, SO, SJP, TO, KT, TH, SH, JK, and HK) independently assessed the quality of the articles. A full quality appraisal of these papers was made using the combined tool based on the AMSTAR checklist ${ }^{11}$ developed to assess the methodological quality of SRs.

Each item was scored as "present" (Yes), "absent" (No), "unclear or inadequately described" (Can not answer), or "not applicable" (n/a). Depending on the study design, some items were not applicable. The " $\mathrm{n} / \mathrm{a}$ " was excluded from calculation for quality assessment. We displayed the percentage of descriptions that were present on all items for the quality assessment of articles. Then, based on the percentage of risk of poor methodology and/or bias, each item was assigned to one of the following categories: good description $(80 \%-100 \%)$, poor description $(50 \%-79 \%)$, or very poor description $(0 \%-49 \%)$. 
Table I The special search strategies

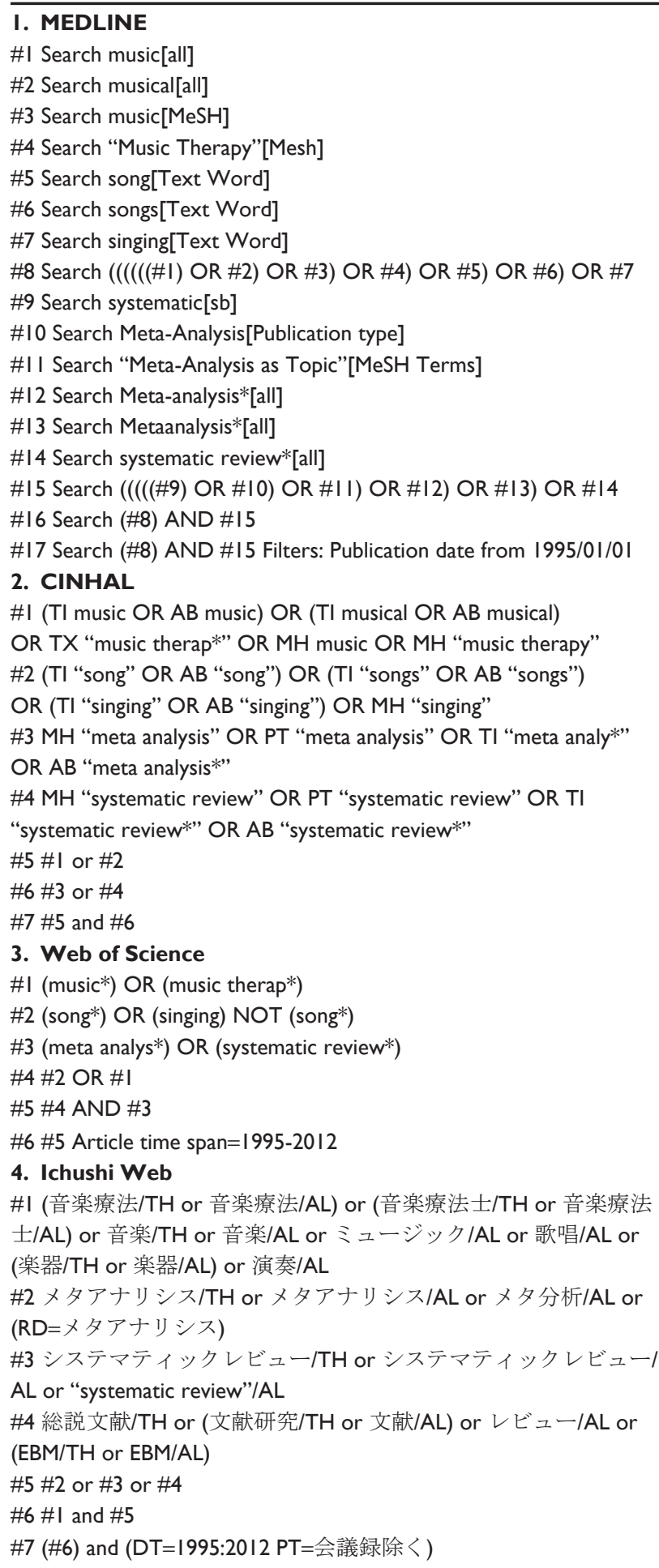

(Continued)
Table I (Continued)

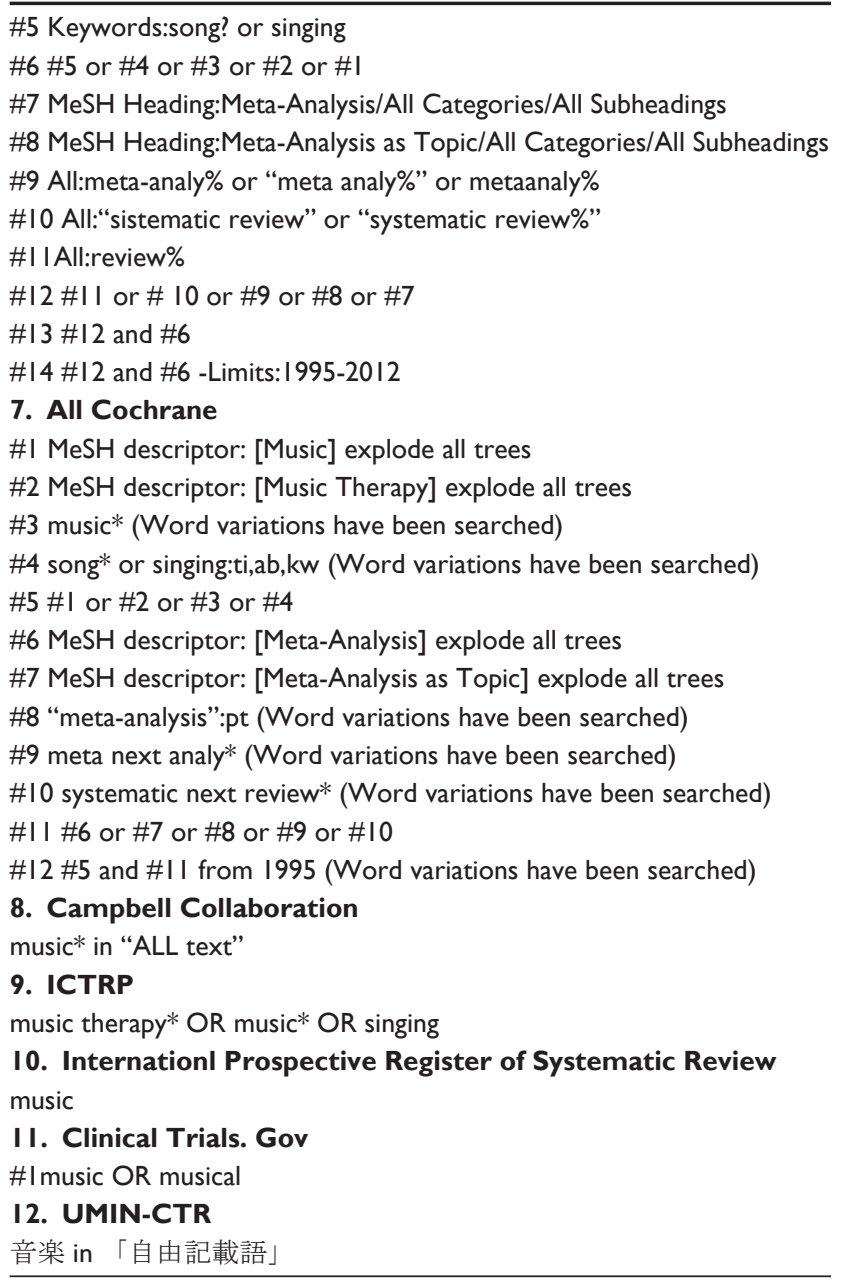

Disagreements and uncertainties were resolved by discussion with other authors (ie, KT and HK). Inter-rater reliability was calculated on a dichotomous scale using percentage agreement and Cohen's kappa coefficient ( $\kappa)$.

\section{Summary of studies and data extraction}

Eleven review authors (HP, MY, HO, SO, SJP, TH, TO, SH, $\mathrm{JK}, \mathrm{KT}$, and HK) described the summary from each article based on the structured abstracts. ${ }^{12,13}$

\section{Benefit and harm}

The GRADE Working Group ${ }^{14}$ reported that the balance between benefit and harm, quality of evidence, applicability, and the certainty of the baseline risk were all considered in judgments about the strength of recommendations. Adverse events for intervention were especially important information for researchers and users of clinical practice guidelines, and we presented this information with the description of each article. 
Table 2 A structured abstract of 21 systematic reviews

\begin{tabular}{|c|c|c|c|c|}
\hline Study & Title & Aim/objective & Data source/search strategy & $\begin{array}{l}\text { Study selection/ } \\
\text { selection criteria }\end{array}$ \\
\hline $\begin{array}{l}\text { Sinha } \\
\text { et a }\left.\right|^{17}\end{array}$ & $\begin{array}{l}\text { Auditory integration } \\
\text { training and other } \\
\text { sound therapies for } \\
\text { autism spectrum } \\
\text { disorders (ASD) }\end{array}$ & $\begin{array}{l}\text { To determine the } \\
\text { effectiveness of auditory } \\
\text { integration therapy or } \\
\text { other methods of sound } \\
\text { therapy in individuals } \\
\text { with autism spectrum } \\
\text { disorders. }\end{array}$ & $\begin{array}{l}\text { For this update, we searched the following } \\
\text { databases in September 20I0: } \\
\text { CENTRAL (20I0, Issue 2), MEDLINE } \\
\text { (I950 to September week 2, 20I0), } \\
\text { EMBASE (I980 to week 38, 20I0), } \\
\text { CINAHL ( } 1937 \text { to current), PsycINFO } \\
\text { (I887 to current), ERIC (I966 to current), } \\
\text { LILACS (September 20I0) and the } \\
\text { reference lists of published papers. } \\
\text { One new study was found for inclusion. }\end{array}$ & $\begin{array}{l}\text { Randomized controlled trials } \\
\text { involving adults or children } \\
\text { with autism spectrum } \\
\text { disorders. Treatment was } \\
\text { auditory integration therapy } \\
\text { or other sound therapies } \\
\text { involving listening to music } \\
\text { modified by filtering and } \\
\text { modulation. Control groups } \\
\text { could involve no treatment, } \\
\text { a waiting list, usual therapy, } \\
\text { or a placebo equivalent. The } \\
\text { outcomes were changes in } \\
\text { core and associated features } \\
\text { of autism spectrum disorders, } \\
\text { auditory processing, QoL, and } \\
\text { adverse events. }\end{array}$ \\
\hline
\end{tabular}

\begin{tabular}{|c|c|c|c|}
\hline $\begin{array}{l}\text { Mossler } \\
\text { et a al }\end{array}$ & $\begin{array}{l}\text { Music therapy for } \\
\text { people with } \\
\text { schizophrenia and } \\
\text { schizophrenia-like } \\
\text { disorders }\end{array}$ & $\begin{array}{l}\text { To review the effects of } \\
\text { music therapy, or music } \\
\text { therapy added to } \\
\text { standard care, compared } \\
\text { with "placebo" therapy, } \\
\text { standard care or no } \\
\text { treatment for people } \\
\text { with serious mental } \\
\text { disorders such as } \\
\text { schizophrenia. }\end{array}$ & $\begin{array}{l}\text { We searched the Cochrane Schizophrenia } \\
\text { Group Trials Register (December 20I0) } \\
\text { and supplemented this by contacting } \\
\text { relevant study authors, handsearching } \\
\text { of music therapy journals, and manual } \\
\text { searches of reference lists. }\end{array}$ \\
\hline
\end{tabular}

All RCTs that compared music therapy with standard care, placebo therapy, or no treatment.

Table 2 (Continued) 


\begin{tabular}{|c|c|c|}
\hline $\begin{array}{l}\text { Data extraction/data } \\
\text { collection and analysis }\end{array}$ & Main results & The authors' conclusions \\
\hline $\begin{array}{l}\text { Two independent review authors } \\
\text { performed data extraction. } \\
\text { All outcome data in the included } \\
\text { papers were continuous. } \\
\text { We calculated point estimates } \\
\text { and standard errors from } \\
\text { paired } t \text {-test scores and post- } \\
\text { intervention means. Meta- } \\
\text { analysis was inappropriate for } \\
\text { the available data. }\end{array}$ & $\begin{array}{l}\text { We identified six RCTs of auditory integration } \\
\text { therapy and one of Tomatis therapy, involving a } \\
\text { total of } 182 \text { individuals aged 3-39 years. Two were } \\
\text { cross-over trials. Five trials had fewer than } 20 \\
\text { participants. Allocation concealment was inadequate } \\
\text { for all studies. Twenty different outcome measures } \\
\text { were used, and only two outcomes were used } \\
\text { by three or more studies. Meta-analysis was not } \\
\text { possible due to very high heterogeneity or the } \\
\text { presentation of data in unusable forms. Three } \\
\text { studies did not demonstrate any benefit of auditory } \\
\text { integration therapy over control conditions. Three } \\
\text { studies reported improvements at } 3 \text { months for } \\
\text { the auditory integration therapy group based on } \\
\text { the Aberrant Behavior Checklist, but they used a } \\
\text { total score rather than subgroup scores, which is of } \\
\text { questionable validity, and Veale's results did not reach } \\
\text { statistical significance. Rimland I } 995 \text { also reported } \\
\text { improvements at } 3 \text { months in the auditory integration }\end{array}$ & $\begin{array}{l}\text { There is no evidence that auditory } \\
\text { integration therapy or other sound } \\
\text { therapies are effective as treatments for } \\
\text { autism spectrum disorders. As synthesis } \\
\text { of existing data has been limited by the } \\
\text { disparate outcome measures used between } \\
\text { studies, there is not sufficient evidence to } \\
\text { prove that this treatment is not effective. } \\
\text { However, of the seven studies including } \\
\text { I82 participants that have been reported to } \\
\text { date, only two (with an author in common), } \\
\text { involving a total of } 35 \text { participants, report } \\
\text { statistically significant improvements in the } \\
\text { auditory integration therapy group and for } \\
\text { only two outcome measures (Aberrant } \\
\text { Behavior Checklist and Fisher's Auditory } \\
\text { Problems Checklist). As such, there is no } \\
\text { evidence to support the use of auditory } \\
\text { integration therapy at this time. }\end{array}$ \\
\hline
\end{tabular}

Studies were reliably selected, quality assessed, and data extracted. We excluded data where more than $30 \%$ of participants in any group were lost to follow-up. We synthesized non-skewed continuous endpoint data from valid scales using an SMD. If statistical heterogeneity was found, we examined treatment "dosage" and treatment approach as possible sources of heterogeneity. therapy group for the Aberrant Behavior Checklist subgroup scores. The study addressing Tomatis therapy described an improvement in language with no difference between treatment and control conditions and did not report on the behavioral outcomes that were used in the auditory integration therapy trials.

We included eight studies (total 483 participants). These examined effects of music therapy over the shortto medium-term (I-4 months), with treatment "dosage" varying from seven to 78 sessions. Music therapy added to standard care was superior to standard care for global state (medium-term, one RCT, $n=72, R R 0.10$, $95 \% \mathrm{Cl}$ 0.03-0.3I; NNT 2, 95\% Cl I.2-2.2). Continuous data identified good effects on negative symptoms (four RCTs, n=240, SMD average endpoint SANS -0.74, $95 \% \mathrm{Cl}-1.00$ to -0.47$)$; general mental state (one RCT, $n=69$, SMD average endpoint PANSS -0.36 , $95 \% \mathrm{Cl}-0.85$ to 0.12 ; two RCTs, $n=100$, SMD average endpoint. BPRS $-0.73,95 \% \mathrm{Cl}-\mathrm{I} .16$ to $-0.3 \mathrm{I}$ ); depression (two RCTs, $\mathrm{n}=90$, SMD average endpoint. SDS $-0.63,95 \% \mathrm{Cl}-1.06$ to -0.21 ; one $\mathrm{RCT}, \mathrm{n}=30$, SMD average endpoint Ham-D $-0.52,95 \% \mathrm{Cl}-1.25$ to -0.12 ); and anxiety (one RCT, $\mathrm{n}=60$, SMD average endpoint SAS $-0.61,95 \% \mathrm{Cl}-1.13$ to -0.09 ).

Positive effects were also found for social functioning (one RCT, $\mathrm{n}=70$, SMD average endpoint. SDSI score $-0.78,95 \% \mathrm{Cl}-1.27$ to -0.28$)$. Furthermore, some aspects of cognitive functioning and behavior seem to develop positively through music therapy. Effects, however, were inconsistent across studies and depended on the number of music therapy sessions as well as the quality of music therapy provided.
Music therapy as an addition to standard care helps people with schizophrenia to improve their global state, mental state (including negative symptoms), and social functioning if a sufficient number of music therapy sessions are provided by qualified music therapists. Further research should especially address the long-term effects of music therapy, dose-response relationships, as well as the relevance of outcomes measures in relation to music therapy. 


\begin{tabular}{lll}
\hline Study & Title & Aim/objective \\
\hline Bradt $^{19}$ & Music interventions for & To compare the effects \\
& $\begin{array}{l}\text { improving psychological } \\
\text { and physical outcomes }\end{array}$ & $\begin{array}{l}\text { of music therapy or music } \\
\text { in cancer patients }\end{array}$ \\
& and standard care with \\
& standard care alone, or \\
& standard care and other \\
& interventions in patients \\
& with cancer.
\end{tabular}

Data source/search strategy

Study selection/

selection criteria

We searched CENTRAL (The Cochrane

We included all RCTs

Library 2010, Issue I0), MEDLINE, EMBASE, and quasi-RCTs of music CINAHL, PsycINFO, LILACS, Science

Citation Index, CancerLit, http://www. musictherapyworld.net, CAIRSS, Pro Quest

Digital Dissertations, ClinicalTrials.gov,

Current Controlled Trials, and the

National Research Register. All databases were searched from their start date to September 2010. We handsearched music therapy journals and reference lists and contacted experts. There was no language restriction. interventions for improving psychological and physical outcomes in patients with cancer. Participants undergoing biopsy and aspiration for diagnostic purposes were excluded.

Bradt and

Dileo $^{20}$

Vink

et $\mathrm{al}^{21}$
Music therapy for end-of-life care
To examine effects of music therapy with standard care versus standard care alone or standard care combined with other therapies on psychological, physiological, and social responses in end-of-life care.
We searched CENTRAL, MEDLINE, CINAHL, EMBASE, PsycINFO, LILACS, CancerLit, Science Citation Index, http://www.musictherapyworld.de, CAIRSS for Music, Pro Quest Digital Dissertations, ClinicalTrials.gov, Current Controlled Trials, and the National Research Register to September 2009.

We handsearched music therapy journals and reference lists, and contacted experts to identify unpublished manuscripts. There was no language restriction.

ALOIS, the specialized Register of the CDCIG was searched on April I4, 2010 using the terms: music therapy, music singing, sing, and auditory stimulation. Additional searches were also carried out on April 14, 2010 in the major health care databases MEDLINE, EMBASE, PsycINFO, CINAHL, and LILACS, trial registers and grey literature sources to ensure the search was as up-to-date and as comprehensive as possible.
We included all RCTs and quasi-RCTs that compared music interventions and standard care with standard care alone or combined with other therapies in any care setting with a diagnosis of advanced life-limiting illness being treated with palliative intent and with a life expectancy of less than 2 years.

Randomized controlled trials that reported clinically relevant outcomes associated with music therapy in treatment of behavioral, social, cognitive, and emotional problems of older people with dementia. to the type of music therapy intervention. emotional problems of older people with dementia, in relation 


\section{Data extraction/data collection and analysis}

Two review authors independently extracted the data and assessed the risk of bias. Where possible, results were presented in meta-analyses using MDs and SMDs. Post-test scores were used. In cases of significant baseline difference, we used change scores.
Data were extracted, and methodological quality was assessed, independently by review authors. Additional information was sought from study authors when necessary. Results are presented using weighted MDs for outcomes measured by the same scale and SMDs for outcomes measured by different scales. Post-test scores were used. In cases of statistically significant baseline difference, we used change scores.

Two reviewers screened the retrieved studies independently for methodological quality. Data from accepted studies were independently extracted by the reviewers.

Main results

The authors' conclusions

We included 30 trials with a total of I,89I participants.

We included music therapy interventions offered by trained music therapists, as well as listening to prerecorded music offered by medical staff. The results suggest that music interventions may have a beneficial effect on anxiety in people with cancer, with a reported average anxiety reduction of II.20 units (95\% Cl -19.59 to $-2.82, P=0.009)$ on the STAI-S scale and $-0.6 \mathrm{I}$ standardized units, $(95 \% \mathrm{Cl}-0.97$ to $-0.26, P=0.0007$ ) on other anxiety scales. Results also suggested a positive impact on mood (SMD $=0.42,95 \% \mathrm{Cl} 0.03-0.8 \mathrm{I}, P=0.03$ ), but no support was found for depression. Music interventions may lead to small reductions in heart rate, respiratory rate, and blood pressure. A moderate pain-reducing effect was found (SMD $=-0.59,95 \% \mathrm{Cl}-0.92$ to -0.27 , $P=0.0003$ ), but no strong evidence was found for enhancement of fatigue or physical status. The pooled estimate of two trials suggested a beneficial effect of music therapy on patients' QoL (SMD $=1.02,95 \% \mathrm{Cl}$ $0.58-1.47, P=0.00001$ ). No conclusions could be drawn regarding the effect of music interventions on distress, body image, oxygen saturation level, immunologic functioning, spirituality, and communication outcomes. Seventeen trials used listening to prerecorded music, and 13 trials used music therapy interventions that actively engaged the patients. Not all studies included the same outcomes, and due to the small number of studies per outcome, we could not compare the effectiveness of music medicine interventions with that of music therapy interventions.

Five studies (I 75 participants) were included.

There is insufficient evidence of high quality to support the effect of music therapy on QoL of people in endof-life care. Given the limited number of studies and small sample sizes, more research is needed. No strong evidence was found for the effect of music therapy on pain or anxiety. These results were based on two small studies. There were insufficient data to examine the effect of music therapy on other physical, psychological, or social outcomes.

Ten studies were included. The methodological quality of the studies was generally poor, and the study results could not be validated or pooled for further analyses.
This systematic review indicates that music interventions may have beneficial effects on anxiety, pain, mood, and QoL in people with cancer. Furthermore, music may have a small effect on heart rate, respiratory rate, and blood pressure. Most trials were at high risk of bias, and therefore, these results need to be interpreted with caution.

A limited number of studies suggest there may be a benefit of music therapy on the QoL of people in end-of-life care. However, the results stem from studies with a high risk of bias. More research is needed.

The methodological quality and the reporting of the included studies were too poor to draw any useful conclusions. 
Table 2 (Continued)

\begin{tabular}{|c|c|c|c|c|}
\hline Study & Title & Aim/objective & Data source/search strategy & $\begin{array}{l}\text { Study selection/ } \\
\text { selection criteria }\end{array}$ \\
\hline $\begin{array}{l}\text { Bradt } \\
\text { et } \mathrm{al}^{22}\end{array}$ & $\begin{array}{l}\text { Music interventions } \\
\text { for mechanically } \\
\text { ventilated patients }\end{array}$ & $\begin{array}{l}\text { To examine the effects } \\
\text { of music interventions } \\
\text { with standard care } \\
\text { versus standard care } \\
\text { alone on anxiety and } \\
\text { physiological responses } \\
\text { in mechanically } \\
\text { ventilated patients. }\end{array}$ & $\begin{array}{l}\text { We searched CENTRAL (The Cochrane } \\
\text { Library 20I0, Issue I) MEDLINE, CINAHL, } \\
\text { AMED, EMBASE, PsycINFO, LILACS, } \\
\text { Science Citation Index, http://www. } \\
\text { musictherapyworld.net, CAIRSS for Music, } \\
\text { Pro Quest Digital Dissertations, } \\
\text { ClinicalTrials.gov, Current Controlled Trials, } \\
\text { the National Research Register, and NIH } \\
\text { RePORTer (formerly CRISP) } \\
\text { (all to January 20I0). We } \\
\text { handsearched music therapy journals } \\
\text { and reference lists and contacted relevant } \\
\text { experts to identify unpublished manuscripts. } \\
\text { There was no language restriction. }\end{array}$ & $\begin{array}{l}\text { We included all RCTs and } \\
\text { quasi-RCTs that compared } \\
\text { music interventions and } \\
\text { standard care with standard } \\
\text { care alone for mechanically } \\
\text { ventilated patients. }\end{array}$ \\
\hline $\begin{array}{l}\text { Cepeda } \\
\text { et } \mathrm{al}^{23}\end{array}$ & Music for pain relief & $\begin{array}{l}\text { To evaluate the effects of } \\
\text { music on acute, chronic, } \\
\text { or cancer pain intensity, } \\
\text { pain relief, and analgesic } \\
\text { requirements. }\end{array}$ & $\begin{array}{l}\text { We searched the Cochrane Library, } \\
\text { MEDLINE, EMBASE, PsycINFO, LILACS, } \\
\text { and the references in retrieved manuscripts. } \\
\text { There was no language restriction. }\end{array}$ & $\begin{array}{l}\text { We included RCTs that } \\
\text { evaluated the effect of } \\
\text { music on any type of pain } \\
\text { in children or adults. We } \\
\text { excluded trials that reported } \\
\text { results of concurrent non- } \\
\text { pharmacological therapies. }\end{array}$ \\
\hline
\end{tabular}




\begin{tabular}{|c|c|c|}
\hline $\begin{array}{l}\text { Data extraction/data } \\
\text { collection and analysis }\end{array}$ & Main results & The authors' conclusions \\
\hline $\begin{array}{l}\text { Two authors independently } \\
\text { extracted the data and } \\
\text { assessed the methodological } \\
\text { quality. Additional information } \\
\text { was sought from the trial } \\
\text { researchers, when necessary. } \\
\text { Results were presented using } \\
\text { MDs for outcomes measured }\end{array}$ & $\begin{array}{l}\text { We included eight trials ( } 213 \text { participants). Listening } \\
\text { to music was the main intervention used, and } \\
\text { seven of the studies did not include a trained music } \\
\text { therapist. Results indicated that listening to music may } \\
\text { be beneficial for anxiety reduction in mechanically } \\
\text { ventilated patients; however, these results need to be } \\
\text { interpreted with caution due to the small sample size. } \\
\text { Findings indicated that listening to music consistently }\end{array}$ & $\begin{array}{l}\text { Listening to music may have a beneficial } \\
\text { effect on heart rate, respiratory rate, and } \\
\text { anxiety in mechanically ventilated patients. } \\
\text { However, the quality of the evidence is not } \\
\text { strong. Most studies examined the effects } \\
\text { of listening to prerecorded music. More } \\
\text { research is needed on the effects of music } \\
\text { offered by a trained music therapist. }\end{array}$ \\
\hline
\end{tabular}

by the same scale and SMDs for outcomes measured by different scales. Post-test scores were used. In cases of significant baseline difference, we used change scores.

Data was extracted by two independent review authors. We calculated the MD in pain intensity levels, percentage of patients with at least $50 \%$ pain relief, and opioid requirements. We converted opioid consumption to morphine equivalents. To explore heterogeneity, studies that evaluated adults, children, acute, chronic, malignant, labor, procedural, or experimental pain were evaluated separately, as well as those studies in which patients chose the type of music.

Two review authors independently assessed methodological quality and extracted data. We present results using MDs (using posttest scores), as all outcomes were measured with the same scale. reduced heart rate and respiratory rate, suggesting a relaxation response. No strong evidence was found for blood pressure reduction. Listening to music did not improve oxygen saturation level. No studies could be found that examined the effects of music interventions on QoL, patient satisfaction, post-discharge outcomes, mortality, or cost-effectiveness.

Fifty-one studies involving 1,867 subjects exposed to music and I,796 controls met inclusion criteria. In the 3 I studies evaluating mean pain intensity there was a considerable variation in the effect of music, indicating statistical heterogeneity $\left(I^{2}=85.3 \%\right)$.

After grouping the studies according to the pain model, this heterogeneity remained, with the exception of the studies that evaluated acute postoperative pain. In this last group, patients exposed to music had pain intensity that was 0.5 units lower on a $0-10$ scale than unexposed subjects $(95 \% \mathrm{Cl}-0.9$ to -0.2$)$. Studies that permitted patients to select the music did not reveal a benefit from music; the decline in pain intensity was 0.2 units, $95 \% \mathrm{Cl}$ ( -0.7 to 0.2 ). Four studies reported the proportion of subjects with at least $50 \%$ pain relief; subjects exposed to music had a $70 \%$ higher likelihood of having pain relief than unexposed subjects (95\% Cl I.2I-2.37). NNT $=5$ (95\% Cl 4-13). Three studies evaluated opioid requirements two hours after surgery: subjects exposed to music required $1.0 \mathrm{mg}$ ( $18.4 \%)$ less morphine $(95 \% \mathrm{Cl}-2.0$ to -0.2$)$ than unexposed subjects. Five studies assessed requirements 24 hours after surgery: the music group required $5.7 \mathrm{mg}$ (15.4\%) less morphine than the unexposed group $(95 \% \mathrm{Cl}-8.8$ to -2.6$)$. Five studies evaluated requirements during painful procedures: the difference in requirements showed a trend towards favoring the music group $(-0.7 \mathrm{mg}, 95 \% \mathrm{Cl}-1.8$ to 0.4$)$. We included seven studies ( 184 participants). The results suggest that RAS may be beneficial for improving gait parameters in stroke patients, including gait velocity, cadence, stride length, and gait symmetry. These results were based on two studies that received a low risk of bias score. There were insufficient data to examine the effect of music therapy on other outcomes.
Listening to music reduces pain intensity levels and opioid requirements, but the magnitude of these benefits is small and, therefore, its clinical importance unclear.
RAS may be beneficial for gait improvement in people with stroke. These results are encouraging, but more RCTs are needed before recommendations can be made for clinical practice. More research is needed to examine the effects of music therapy on other outcomes in people with acquired brain injury. 
Table 2 (Continued)

\begin{tabular}{|c|c|c|c|c|}
\hline Study & Title & Aim/objective & Data source/search strategy & $\begin{array}{l}\text { Study selection/ } \\
\text { selection criteria }\end{array}$ \\
\hline $\begin{array}{l}\text { Gold } \\
\text { et } \mathrm{al}^{25}\end{array}$ & $\begin{array}{l}\text { Music therapy for } \\
\text { autistic spectrum } \\
\text { disorder }\end{array}$ & $\begin{array}{l}\text { To review the effects } \\
\text { of music therapy for } \\
\text { individuals with autistic } \\
\text { spectrum disorders. }\end{array}$ & $\begin{array}{l}\text { The following databases were searched: } \\
\text { CENTRAL, } 2005 \text { (issue 3); MEDLINE (I } 966 \\
\text { to July 2004); EMBASE (I } 980 \text { to July 2004); } \\
\text { LILACS (I } 982 \text { to July 2004); PsycINFO } \\
\text { (I872 to July 2004); CINAHL, (I872 to July } \\
2004 \text { ); ERIC (I } 966 \text { to July 2004); ASSIA } \\
\text { (I987 to July 2004); Sociofile (I } 963 \text { to July } \\
2004) ; \text { Dissertation Abstracts International } \\
\text { (late I960s to July 2004). These searches } \\
\text { were supplemented by searching specific } \\
\text { sources for music therapy literature and } \\
\text { manual searches of reference lists. Personal } \\
\text { contacts to some investigators were made. }\end{array}$ & $\begin{array}{l}\text { All RCTs or controlled } \\
\text { clinical trials comparing music } \\
\text { therapy added to standard } \\
\text { care to "placebo" therapy, no } \\
\text { treatment, or standard care. }\end{array}$ \\
\hline $\begin{array}{l}\text { Laopaiboon } \\
\text { et } \mathrm{al}^{26}\end{array}$ & $\begin{array}{l}\text { Music during } \\
\text { caesarean section } \\
\text { under regional } \\
\text { anesthesia for } \\
\text { improving maternal } \\
\text { and infant outcomes }\end{array}$ & $\begin{array}{l}\text { To evaluate the } \\
\text { effectiveness of music } \\
\text { during cesarean section } \\
\text { under regional anesthesia } \\
\text { for improving clinical and } \\
\text { psychological outcomes }\end{array}$ & $\begin{array}{l}\text { We searched the Cochrane Pregnancy } \\
\text { and Childbirth Group's Trials Register } \\
\text { (30 September 2008). }\end{array}$ & $\begin{array}{l}\text { We included randomized } \\
\text { controlled trials comparing } \\
\text { music added to standard } \\
\text { care during cesarean section } \\
\text { under regional anesthesia to } \\
\text { standard care alone. }\end{array}$ \\
\hline
\end{tabular}

Bradt and Music for stress and To examine the effects Dileo $^{27} \quad$ anxiety reduction in coronary heart disease patients

Maratos Music therapy for et $\mathrm{a}^{28}$ depression of music interventions with standard care versus standard care alone on psychological and physiological responses in persons with $\mathrm{CHD}$.
To examine the efficacy of music therapy with standard care compared with standard care alone among people with depression and to compare the effects of music therapy for people with depression against other psychological or pharmacological therapies.
We searched CENTRAL, MEDLINE, CINAHL, EMBASE, PsycINFO, LILACS, Science Citation Index, http://www. musictherapyworld.net, CAIRSS for Music, Pro Quest Digital Dissertations, ClinicalTrials.gov, Current Controlled Trials, and the National Research Register (all to May 2008). We handsearched music therapy journals and reference lists, and contacted relevant experts to identify unpublished manuscripts. There was no language restriction.

CCDANCTR studies and CCDANCTR references were searched on November 7, 2007, and MEDLINE, PsycINFO, EMBASE, PsycLIT, PSYindex, and other relevant sites were searched in November 2006. Reference lists of retrieved articles were handsearched, as well as specialist music and arts therapies journals.
We included all RCTs that compared music interventions and standard care with standard care alone for persons with CHD.
All RCTs comparing music therapy with standard care or other interventions for depression. 


\begin{tabular}{|c|c|c|}
\hline $\begin{array}{l}\text { Data extraction/data } \\
\text { collection and analysis }\end{array}$ & Main results & The authors' conclusions \\
\hline $\begin{array}{l}\text { Studies were independently } \\
\text { selected, quality assessed, and } \\
\text { data extracted by two authors. } \\
\text { Continuous outcomes were } \\
\text { synthesized using an SMD to } \\
\text { enable a meta-analysis combining } \\
\text { different scales, and to facilitate } \\
\text { the interpretation of effect sizes. } \\
\text { Heterogeneity was assessed }\end{array}$ & $\begin{array}{l}\text { Three small studies were included (total } n=24 \text { ). } \\
\text { These examined the short-term effect of brief music } \\
\text { therapy interventions (daily sessions over I week) } \\
\text { for autistic children. Music therapy was superior to } \\
\text { "placebo" therapy with respect to verbal and gestural } \\
\text { communicative skills (verbal, two RCTs, } n=20 \text {, } \\
\text { SMD } 0.36,95 \% \mathrm{Cl} 0.15-0.57 \text {; gestyrak, } 2 \mathrm{RCTs}, \mathrm{n}=20 \text {, } \\
\text { SMD } 0.50,95 \% \mathrm{Cl} 0.22-0.79 \text { ). Effects on behavioral } \\
\text { problems were not significant. }\end{array}$ & $\begin{array}{l}\text { The included studies were of limited } \\
\text { applicability to clinical practice. However, } \\
\text { the findings indicate that music therapy } \\
\text { may help children with autistic spectrum } \\
\text { disorder to improve their communicative } \\
\text { skills. More research is needed to examine } \\
\text { whether the effects of music therapy are } \\
\text { enduring, and to investigate the effects of } \\
\text { music therapy in typical clinical practice. }\end{array}$ \\
\hline
\end{tabular}

Two review authors, Malinee Laopaiboon and Ruth Martis, independently assessed eligibility, risk of bias in included trials and extracted data. We analyzed continuous outcomes using an MD with a $95 \% \mathrm{Cl}$.

Data were extracted and methodological quality was assessed, independently by the two reviewers. Additional information was sought from the trial researchers when necessary. Results are presented using weighted MDs for outcomes measured by the same scale and SMDs for outcomes measured by different scales. Post-test scores were used. In cases of significant baseline difference, we used change scores.

Data on participants, interventions, and outcomes were extracted and entered into a database independently by two review authors. The methodological quality of each study was also assessed independently by two review authors. The primary outcome was reduction in symptoms of depression, based on a continuous scale.
One trial involving 76 women who planned to have their babies delivered by cesarean section met the inclusion criteria, but data were available for only 64 women. This trial was of low quality with unclear allocation concealment, and only a few main clinical outcomes reported for the women. The trial did not report any infant outcomes. It appears that music added to standard care during cesarean section under regional anesthesia had some impact on pulse rate at the end of maternal contact with the neonate in the intra-operative period (MD -7.50 fewer beats per minute, $95 \% \mathrm{Cl} \mathrm{I4.08} \mathrm{to}-0.92$ ) and after completion of skin suture for the cesarean section (MD -7.37 fewer beats per minute, $95 \% \mathrm{Cl}$ 13.37-1.37). There was also an improvement in the birth satisfaction score (maximum possible score of 35 ) (MD of $3.38,95 \% \mathrm{Cl}$ 1.59-5.17). Effects on other outcomes were either not significant or not reported in the one included trial. Twenty-three trials (I,46I participants) were included. Listening to music was the main intervention used, and $2 \mathrm{I}$ of the studies did not include a trained music therapist. Results indicated that listening to music has a moderate effect on anxiety in patients with CHD; however, results were inconsistent across studies. This review did not find strong evidence for reduction of psychological distress. Findings indicated that listening to music reduces heart rate, respiratory rate, and blood pressure. Studies that included two or more music sessions led to a small and consistent pain-reducing effect. No strong evidence was found for peripheral skin temperature. None of the studies considered hormone levels, and only one study considered $\mathrm{QoL}$ as an outcome variable.

Five studies met the inclusion criteria of the review. Marked variations in the interventions offered and the populations studied meant that meta-analysis was not appropriate. Four of the five studies individually reported greater reduction in symptoms of depression among those randomized to music therapy than to those in standard care conditions. The fifth study, in which music therapy was used as an active control treatment, reported no significant change in mental state for music therapy compared with standard care. Dropout rates from music therapy conditions appeared to be low in all studies.
The findings indicate that music during planned cesarean section under regional anesthesia may improve pulse rate and birth satisfaction score. However, the magnitude of these benefits is small and the methodological quality of the one included trial is questionable. Therefore, the clinical significance of music is unclear. More research is needed to investigate the effects of music during cesarean section under regional anesthesia on both maternal and infant outcomes, in various ethnic pregnant women, and with adequate sample sizes.

Listening to music may have a beneficial effect on blood pressure, heart rate, respiratory rate, anxiety, and pain in persons with CHD. However, the quality of the evidence is not strong and the clinical significance unclear. Most studies examined the effects of listening to prerecorded music. More research is needed on the effect of music offered by a trained music therapist.

Findings from individual randomized trials suggest that music therapy is accepted by people with depression and is associated with improvements in mood. However, the small number and low methodological quality of studies mean that it is not possible to be confident about its effectiveness. High quality trials evaluating the effects of music therapy on depression are required. 
Table 2 (Continued)

\begin{tabular}{|c|c|c|c|c|}
\hline Study & Title & Aim/objective & Data source/search strategy & $\begin{array}{l}\text { Study selection/ } \\
\text { selection criteria }\end{array}$ \\
\hline $\begin{array}{l}\text { de Dreu } \\
\text { et } \mathrm{al}^{29}\end{array}$ & $\begin{array}{l}\text { Rehabilitation, } \\
\text { exercise therapy and } \\
\text { music in patients with } \\
\text { Parkinson's disease: } \\
\text { a meta-analysis of the } \\
\text { effects of music-based } \\
\text { movement therapy on } \\
\text { walking ability, balance } \\
\text { and quality of life }\end{array}$ & $\begin{array}{l}\text { To study that people with } \\
\text { PD benefit from MbM } \\
\text { therapy when compared } \\
\text { with conventional } \\
\text { therapy or no therapy } \\
\text { in terms of standing } \\
\text { balance, transfers, gait } \\
\text { performance, severity of } \\
\text { freezing, and QoL. }\end{array}$ & $\begin{array}{l}\text { We searched PubMed, EMBASE, Cochrane, } \\
\text { CINAHL, and SPORTDiscus for articles } \\
\text { published until Ist August, 20II. }\end{array}$ & $\begin{array}{l}\text { The following selection } \\
\text { criteria were applied: I) } \\
\text { people with PD were } \\
\text { targeted, } 2 \text { ) the study was } \\
\text { an RCT of high quality } \\
\text { (PEDro score of }>4 \text { ), 3) the } \\
\text { intervention contained MbM, } \\
\text { and 4) the rhythmic cues } \\
\text { were embedded in music. }\end{array}$ \\
\hline $\begin{array}{l}\text { Cogo- } \\
\text { Moreira } \\
\text { et } \mathrm{al}^{30}\end{array}$ & $\begin{array}{l}\text { Music education for } \\
\text { improving reading } \\
\text { skills in children and } \\
\text { adolescents with } \\
\text { dyslexia }\end{array}$ & $\begin{array}{l}\text { To study the effectiveness } \\
\text { of music education on } \\
\text { reading skills (ie, oral } \\
\text { reading skills, reading } \\
\text { comprehension, reading } \\
\text { fluency, phonological } \\
\text { awareness, and spelling) } \\
\text { in children and } \\
\text { adolescents with dyslexia. }\end{array}$ & $\begin{array}{l}\text { We searched the following electronic } \\
\text { databases in June 20I2: CENTRAL ( } 20 \text { I2, } \\
\text { Issue 5), MEDLINE (I948 to May week } 4 \\
20 \text { I2), EMBASE (I } 980 \text { to } 20 \text { I } 2 \text { week 22), } \\
\text { CINAHL (searched June 7, 20I2), LILACS } \\
\text { (searched June 7, 20I2), PsycINFO (I887 to } \\
\text { May week } 5 \text { 20I2), ERIC (searched June 7, } \\
20 I 2 \text { ), Arts and Humanities Citation } \\
\text { Index (I } 970 \text { to } 6 \text { June 20I2), Conference } \\
\text { Proceedings Citation Index - Social Sciences } \\
\text { and Humanities (I990 to June 20I2), } \\
\text { and WorldCat (searched June 7, 20I2). } \\
\text { We also searched the WHO ICTRP and } \\
\text { reference lists of studies. We did not apply } \\
\text { any date or language limits. }\end{array}$ & $\begin{array}{l}\text { We planned to include RCTs. } \\
\text { We looked for studies that } \\
\text { included at least one of our } \\
\text { primary outcomes. The } \\
\text { primary outcomes were } \\
\text { related to the main domain } \\
\text { of reading: oral reading skills, } \\
\text { reading comprehension, } \\
\text { reading fluency, phonological } \\
\text { awareness, and spelling } \\
\text { measured through validated } \\
\text { instruments. The secondary } \\
\text { outcomes were self-esteem } \\
\text { and academic achievement. }\end{array}$ \\
\hline $\begin{array}{l}\text { Drahota } \\
\text { et } \mathrm{al}^{31}\end{array}$ & $\begin{array}{l}\text { Sensory environment } \\
\text { on health-related } \\
\text { outcomes of hospital } \\
\text { patients }\end{array}$ & $\begin{array}{l}\text { To assess the effect of } \\
\text { hospital environments } \\
\text { on adult patient health- } \\
\text { related outcomes. }\end{array}$ & $\begin{array}{l}\text { We searched: CENTRAL (last searched } \\
\text { January 2006); MEDLINE (I } 902 \text { to } \\
\text { December 2006); EMBASE (January I } 980 \\
\text { to February 2006); I } 4 \text { other databases } \\
\text { covering health, psychology, and the } \\
\text { built environment; reference lists; and } \\
\text { organization websites. This review is } \\
\text { currently ongoing (MEDLINE last search } \\
\text { October 20I0), see Studies awaiting } \\
\text { classification. }\end{array}$ & $\begin{array}{l}\text { RCTs and non-randomized } \\
\text { controlled trials, before-and- } \\
\text { after studies, and interrupted } \\
\text { times series of environmental } \\
\text { interventions in adult hospital } \\
\text { patients reporting health- } \\
\text { related outcomes. }\end{array}$ \\
\hline
\end{tabular}




\section{Data extraction/data collection and analysis}

Two reviewers extracted relevant data from the included studies. A meta-analysis of RCTs on the efficacy of MbM therapy, including individual rhythmic music training and partnered dance classes, was performed. Identified studies $(\mathrm{N}=6)$ were evaluated on methodological quality, and SESs were calculated. Two authors (HCM and RBA) independently screened all titles and abstracts identified through the search strategy to determine their eligibility. For our analysis we had planned to use MD for continuous data, with $95 \% \mathrm{Cls}$, and to use the random-effects statistical model when the effect estimates of two or more studies could be combined in a metaanalysis.

Two review authors independently undertook data extraction and "risk of bias" assessment. We contacted authors to obtain missing information. For continuous variables, we calculated an MD or SMD, and $95 \% \mathrm{Cls}$ for each study. For dichotomous variables, we calculated RR with $95 \% \mathrm{Cl}$. When appropriate, we used a random-effects model of meta-analysis. Heterogeneity was explored qualitatively and quantitatively based on risk of bias, case mix, hospital visit characteristics, and country of study.

\section{Main results}

Studies were generally small (total $N=168$ ). Significant homogeneous SESs were found for the Berg Balance Scale, Timed Up and Go test, and stride length (SESs, 4.I, 2.2, and 0.II; $P$-values $<0.0 \mathrm{I}$; $\mathrm{I}^{2}, 0 \%, 0 \%$, and $7 \%$, respectively). A sensitivity analysis on type of MbM therapy (dance- or gait-related interventions) revealed a significant improvement in walking velocity for gait-related MbM therapy but not for dance-related MbM therapy. No significant effects were found for UPDRS-motor score, freezing of gait, and QoL. We retrieved $85 \mathrm{I}$ references via the search strategy. No RCTs testing music education for the improvement of reading skills in children with dyslexia could be included in this review.
Overall, 102 studies were included in this review. Interventions explored were: "positive distracters", to include aromas (two studies), audiovisual distractions (five studies), decoration (one study), and music (85 studies); interventions to reduce environmental stressors through physical changes, to include air quality (three studies), bedroom type (one study), flooring (two studies), furniture and furnishings (one study), lighting (one study), and temperature (one study); and multifaceted interventions (two studies). We did not find any studies meeting the inclusion criteria to evaluate: art, access to nature for example through hospital gardens, atriums, flowers, and plants, ceilings, interventions to reduce hospital noise, patient controls, technologies, way-finding aids, or the provision of windows. Overall, it appears that music may improve patient-reported outcomes such as anxiety; however, the benefit for physiological outcomes, and medication consumption has less support.

There are few studies to support or refute the implementation of physical changes, and except for air quality, the included studies demonstrated that physical changes in the hospital environment at least did no harm.

\section{The authors' conclusions}

MbM therapy appears promising for the improvement of gait and gait-related activities in PD. Future studies should incorporate larger groups and focus on long-term compliance and follow-up.

There is no evidence available from RCTs on which to base a judgment about the effectiveness of music education for the improvement of reading skills in children and adolescents with dyslexia. This uncertainty warrants further research via RCTs, involving an interdisciplinary team: musicians, hearing and speech therapists, psychologists, and physicians.
Music may improve patient-reported outcomes in certain circumstances, so support for this relatively inexpensive intervention may be justified. For some environmental interventions, well designed research studies have yet to take place. 
Table 2 (Continued)

\begin{tabular}{llll}
\hline Study & Title & Aim/objective & Data source/search strategy \\
\hline Chan & The effectiveness & To review trials of the & A comprehensive search strategy was \\
et $\mathrm{al}^{32}$ & of music listening in & effectiveness of listening & employed to identify all published papers in \\
& reducing depressive & to music in reducing & English language between January I 989 and \\
& symptoms in adults: & depressive symptoms in & March 20I0. We searched nine databases \\
& a systematic review & adults, and identify areas & with initial search terms including "music", \\
& & requiring further study. & "depression", or "depressive symptoms".
\end{tabular}

$\begin{array}{llll}\begin{array}{l}\text { Naylor } \\ \text { et al }{ }^{33}\end{array} & \begin{array}{l}\text { The effectiveness of } \\ \text { music in pediatric } \\ \text { healthcare: a systematic } \\ \text { review of randomized } \\ \text { controlled trials }\end{array} & \begin{array}{l}\text { To systematically review } \\ \text { the effectiveness of music } \\ \text { on pediatric health- } \\ \text { related outcomes. }\end{array} & \begin{array}{l}\text { The following international electronic } \\ \text { databases were searched on March 4, } \\ \text { 2009: Ovid Medline (Medical Literature } \\ \end{array} \\ & & \begin{array}{l}\text { Analysis and Retrieval System Online), } \\ \text { I950 to February, week 3, 2009; EMBASE, } \\ \end{array} & \begin{array}{l}\text { I980-2009 week 9; PsycINFO, I967 to } \\ \text { February, week 4, 2009; AMED (Allied and } \\ \text { Complementary Medicine), I985-February }\end{array} \\ & & \text { 2009; and CINAHL, I983-2008. }\end{array}$

Study selection/

We searched the published

literature for RCTs and

quasi-experimental trials that included an intervention with music listening designed to reduce the depression level, compared with a control group. The intervention was music listening, it is defined as listening to music via any form of music device or live music, without the active involvement of a music therapist.

Studies were included if they met the following six criteria: I) examined the effectiveness of a music intervention;

2) involved a clinical population in a health care, research, or education setting; 3 ) involved children and adolescents between I and 18 years of age (or reported a mean age within this range); 4) used an RCT design (parallel or crossover); 5) reported at least one quantifiable outcome measure; and 6) was published between 1984 and 2009.

RCTs in which singing (as an adjunctive intervention) is compared with either a sham intervention or no singing in people with cystic fibrosis.

RCTs in which singing (as an intervention) is compared with either a sham intervention or no singing in patients with bronchiectasis. muscle strength, and pulmonary function of children and adults with bronchiectasis.

To evaluate the efficacy

of music-assisted relaxation for sleep quality in adults and elders with sleep complaints with or without a comorbid medical condition.
We searched the Group's Cystic Fibrosis Trials Register, the CENTRAL, major trial registers. Handsearching for relevant conference proceedings and journals was also carried out. Date of search of trials register: September 2, 2009. Date of additional searches: September 17, 2009. We searched the CAG trial register, CENTRAL, major allied complementary databases, and clinical trials registers. Professional organizations and individuals were also contacted. CAG performed searches in February 20 II, and additional searches were carried out in February $201 \mathrm{I}$.

We conducted searches in EMBASE (1997-July 2008), Medline (1950-July 2008), Cochrane (2000-July 2008), PsycINFO (1987-July 2008) and CINAHL (1982-July 2008) for studies published in English, German, French, or Dutch.
We included published RCTs performed in an adult (I8-60 years) or elderly (60 years or older) population with primary sleep complaints or sleep complaints comorbid with a medical condition. Studies involving active use of music, such as playing instruments, were excluded. 


\section{Data extraction/data collection and analysis}

The data extracted included specific details about the interventions, populations, study methods, and outcomes of significance to the review question and specific objectives. Two studies were pooled together for meta-analysis due to similarity in outcome measures and intervention time points.

Data extraction includes information about each study (authorship, year of publication, country, recruitment setting, and experimental design), participants (sample size, sex, population, and age), intervention (treatment, delivery, participant involvement, and dosage), and quality rating. Because of heterogeneity in the study populations, interventions used, and outcome measures applied, it was neither feasible nor appropriate to conduct a

No trials were found that met the selection criteria. meta-analysis.

\section{Main results}

Listening to music over a period of time helps to reduce depressive symptoms in the adult population. Daily intervention does not seem to be superior over weekly intervention, and it is recommended that music listening sessions be conducted repeatedly over a time span of more than 3 weeks to allow an accumulative effect to occur.

Qualitative synthesis revealed significant improvements in one or more health outcomes within four of seven trials involving children with learning and developmental disorders; two of three trials involving children experiencing stressful life events; and four of five trials involving children with acute and/or chronic physical illness. No significant effects were found for two trials involving children with mood disorders and related psychopathology.

No meta-analysis could be performed.

No meta-analysis could be performed.

Two authors independently reviewed the titles, abstracts, and citations to assess potential relevance for full review.

No eligible trials were identified and thus no data were available for analysis.

Pre and post-test means and standard deviations, demographic data, and condition properties were extracted from each included study. Review Manager 5.0.12 (The Cochrane Collaboration, Oxford, UK) was used to calculate the effect sizes of the individual studies and for calculation of the pooled MD.
The authors' conclusions

All types of music can be used as listening material, depending on the preferences of the listener. It is recommended that the listeners are given choices over the kind of music they listen to. There is a need to conduct more studies, which replicate the designs used in the existing studies that met the inclusion criteria, on the level of efficacy of music listening and on the reduction of depressive symptoms for a more accurate meta-analysis of the findings and which would reflect with greater accuracy the significant effects that music has on the level of depressive symptoms. These findings offer limited qualitative evidence to support the effectiveness of music on health-related outcomes for children and adolescents with clinical diagnoses. Recommendations for establishing a consensus on research priorities and addressing methodological limitations are put forth to support the continued advancement of this popular intervention.

As no studies that met the criteria were found, this review is unable to support or refute the benefits of singing as a therapy for people with cystic fibrosis. Future RCTs are required to evaluate singing therapy for people with cystic fibrosis.

In the absence of data, we cannot draw any conclusion to support or refute the adoption of singing as an intervention for people with bronchiectasis. Given the simplicity of the potentially beneficial intervention, future RCTs are required to evaluate singing therapy for people with bronchiectasis.

Music-assisted relaxation can be used without intensive investment in training and materials and is therefore cheap, easily available, and can be used by nurses to promote music-assisted relaxation to improve sleep quality. 
Table 2 (Continued)

\begin{tabular}{|c|c|c|c|c|}
\hline Study & Title & Aim/objective & Data source/search strategy & $\begin{array}{l}\text { Study selection/ } \\
\text { selection criteria }\end{array}$ \\
\hline $\begin{array}{l}\text { Gold } \\
\text { et } \mathrm{al}^{37}\end{array}$ & $\begin{array}{l}\text { Dose-response } \\
\text { relationship in music } \\
\text { therapy for people } \\
\text { with serious mental } \\
\text { disorders: systematic } \\
\text { review and meta- } \\
\text { analysis }\end{array}$ & $\begin{array}{l}\text { To examine the benefits } \\
\text { of music therapy for } \\
\text { people with serious } \\
\text { mental disorders. }\end{array}$ & $\begin{array}{l}\text { A comprehensive search strategy was } \\
\text { applied to identify all relevant studies. } \\
\text { The trial database PsiTri, which contains } \\
\text { structured information on published and } \\
\text { unpublished clinical trials in mental health, } \\
\text { based on multiple database searches as } \\
\text { well as handsearches by several Cochrane } \\
\text { groups, was searched for entries containing } \\
\text { the word "music" in any field. PubMed was } \\
\text { searched using its "Clinical Queries" search } \\
\text { strategy designed to identify scientifically } \\
\text { strong studies of therapy outcome, } \\
\text { which was expanded with the MeSH } \\
\text { term "Evaluation Studies", and crossed } \\
\text { with the MeSH terms "Music Therapy" } \\
\text { and "Mentally III Persons" or "Mental } \\
\text { Disorders". }\end{array}$ & $\begin{array}{l}\text { Study participants eligible for } \\
\text { this review were adults with } \\
\text { serious mental disorders } \\
\text { diagnosed by an international } \\
\text { classification system. This } \\
\text { included psychotic disorders } \\
\text { as well as some non-psychotic } \\
\text { disorders such as borderline } \\
\text { personality disorder, } \\
\text { depression, bipolar disorder, } \\
\text { and suicidality connected to a } \\
\text { mental disorder. Studies were } \\
\text { included only if participants } \\
\text { were offered music therapy, } \\
\text { according to the definition } \\
\text { above. Most importantly, this } \\
\text { excluded interventions of the } \\
\text { "music medicine" type, where } \\
\text { music alone is provided as a } \\
\text { treatment, rather than using } \\
\text { music as a medium within a } \\
\text { psychotherapeutic process } \\
\text { and relationship. Secondly, } \\
\text { it had to be possible to } \\
\text { disentangle music therapy } \\
\text { from other therapies. }\end{array}$ \\
\hline
\end{tabular}

Abbreviations: ASSIA, Applied Social Sciences Index and Abstracts; BPRS, Brief Psychiatric Rating Scale; CAG, Cochrane Airways Group; CAIRSS, Computer-Assisted Information Retrieval System; CCDANCTR, Cochrane Collaboration Depression, Anxiety and Neurosis Controlled Trials Register; CDCIG, Cochrane Dementia and Cognitive Improvement Group; CENTRAL, Cochrane Central Register of Controlled Trials; CHD, coronary heart disease; Cl, confidence interval; CINAHL, Cumulative Index of Nursing and Allied Health Literature; ERIC, Education Resource Information Centre; Ham-D, Hamilton Depression Scale; ICTRP, International Clinical Trials Registry Platform; LILACS, Latin American and Caribbean Health Sciences Literature; MbM, music-based movement; MD, mean difference; MeSH, Medical Subject Headings; $\mathrm{NIH}$, National Institutes of Health; NNT, number needed to treat; PANSS, Positive and Negative Symptoms Scale; PD, Parkinson's disease; PEDro, Physiotherapy Evidence Database; QoL, quality of life; RAS, rhythmic auditory stimulation; RCT, randomized controlled trial; RR, risk ratio; SANS, Scale for the Assessment of Negative Symptoms; SDS, Self-rating Depression Scale; SDSI, Social Disability Schedule for Inpatients; SES, summary effect size; SMD, standardized mean difference; STAI-S, State-Trait Anxiety Inventory - State; UPDRS, Unified Parkinson's Disease Rating Scale; WHO, World Health Organization.

\section{Research protocol registration}

We submitted and registered our research protocol to the PROSPERO (no 42012002950). PROSPERO is an international database of prospectively registered SRs in health and social care. ${ }^{15}$ Key features from the review protocol are recorded and maintained as a permanent record in PROSPERO. This provides a comprehensive listing of SRs registered at inception, and enables comparison of reported review findings with what was planned in the protocol. PROSPERO is managed by UK Centre for Reviews and Dissemination (CRD) and funded by the UK National Institute for Health Research. Registration was recommended because it encourage full publication of the review's findings and transparency in changes to methods that could bias findings. ${ }^{16}$

\section{Results}

\section{Study selection}

The literature searches included potentially relevant articles (Figure 1). Abstracts from those articles were assessed, and
63 papers were retrieved for further evaluation (checks for relevant literature). Forty-two publications were excluded because they did not meet the eligibility criteria (Table S1). A total of 21 studies ${ }^{17-37}$ met all inclusion criteria (Table 1). The language of all eligible publications was English.

\section{Study characteristics}

The contents of all articles were summarized as structured abstracts (Table 2). Sinha et $\mathrm{al}^{17}$ reported that there was no evidence that auditory integration therapy or other sound therapies are effective as treatments for autism spectrum disorders. Mossler et $\mathrm{al}^{18}$ concluded that MT as an addition to standard care helps people with schizophrenia to improve their global state, mental state (including negative symptoms), and social functioning if a sufficient number of MT sessions are provided by qualified music therapists. Bradt et $\mathrm{al}^{19}$ indicated that music interventions may have beneficial effects on anxiety, pain, mood, and quality of life (QoL) in people with cancer. Bradt and Dileo ${ }^{20}$ reported that there may be a benefit of MT on QoL 


\begin{tabular}{lll}
\hline $\begin{array}{l}\text { Data extraction/data } \\
\text { collection and analysis }\end{array}$ & Main results & The authors' conclusions \\
\hline $\begin{array}{l}\text { Results for the same type of } \\
\text { outcome were combined across }\end{array}$ & $\begin{array}{l}\text { Results showed that music therapy, when added to } \\
\text { standard care, has strong and significant effects on }\end{array}$ & The findings suggest that music therapy \\
$\begin{array}{l}\text { studies in a meta-analysis. Results } \\
\text { of different outcomes were not }\end{array}$ & global state, general symptoms, negative symptoms, & people with psychotic and non-psychotic \\
combined. If the same outcome & depression, anxiety, functioning, and musical & severe mental disorders to improve global \\
was measured with different & were identified for general, negative, and depressive & state, symptoms, and functioning. Slight \\
scales in the same study, both & symptoms, as well as functioning, with explained & improvements can be seen with a few \\
using equally valid methods & variance ranging from 73\% to 78\%. Small effect sizes for & more frequent sessions are needed to \\
(in terms of rater blinding and & these outcomes are achieved after 3-I0, large effects & achieve more substantial benefits. \\
standardization and validity of & after $16-5$ I sessions. &
\end{tabular}

instrument), the average effect

size of these measures was used.

of people in end-of-life care. Vink et $\mathrm{al}^{21}$ reported that the methodological quality and the reporting of the included studies on dementia were too poor to draw any useful conclusions. Bradt et $\mathrm{al}^{22}$ indicated that listening to music may have a beneficial effect on heart rate, respiratory rate, and anxiety in mechanically ventilated patients. Cepeda et $\mathrm{al}^{23}$ reported that listening to music reduces pain intensity levels and opioid requirements on patients with chronic, acute, neuropathic, and cancer pain or experimental pain, but the magnitude of these benefits is small and therefore its clinical importance unclear. Bradt et $\mathrm{al}^{24}$ reported that rhythmic auditory stimulation might be beneficial for gait improvement in people with stroke. Gold et $\mathrm{al}^{25}$ indicated that MT may help children with autistic spectrum disorder to improve their communicative skills. Laopaiboon et $\mathrm{al}^{26}$ indicated that music during planned cesarean section under regional anesthesia may improve pulse rate and birth satisfaction score. Bradt and Dileo ${ }^{27}$ reported that listening to music may have a beneficial effect on blood pressure, heart rate, respiratory rate, anxiety, and pain in persons with coronary heart disease. Maratos et $\mathrm{al}^{28}$ suggested that MT is accepted by people with depression and is associated with improvements in mood, but the small number and low methodological quality of studies meant that it is not possible to be confident about its effectiveness. de Dreu et $\mathrm{al}^{29}$ reported that music-based movement therapy appeared promising for the improvement of gait and gait-related activities in Parkinson's disease. Cogo-Moreira et $\mathrm{al}^{30}$ concluded that there is no evidence available on which to base a judgment about the effectiveness of music education for the improvement of reading skills in children and adolescents with dyslexia. Drahota et $\mathrm{al}^{31}$ reported that music may improve patient-reported outcomes in certain circumstances such as anxiety for hospital patients. Chan et $\mathrm{al}^{32}$ concluded that listening to music over a period of time helps to reduce depressive symptoms in the adult population. Naylor et $\mathrm{al}^{33}$ reported that there is limited qualitative evidence to support the effectiveness of music on health-related outcomes for children and adolescents with clinical diagnoses. Irons et $\mathrm{al}^{34}$ concluded that because no studies that met the criteria were found, their 
review was unable to support or refute the benefits of singing as a therapy for people with cystic fibrosis. Irons et al ${ }^{35}$ reported that they could not draw any conclusion to support or refute the adoption of singing as an intervention for people with bronchiectasis because of the absence of data. de Niet et $\mathrm{al}^{36}$ concluded that music-assisted relaxation could be without intensive investment in training and materials and is therefore cheap, easily available and can be used by nurses to promote music-assisted relaxation to improve sleep quality. Gold et $\mathrm{al}^{37}$ reported that MT is an effective treatment which helps people with psychotic and nonpsychotic severe mental disorders to improve global state, symptoms, and functioning.

Based on ICD-10, we identified a disease targeted in each article (Table 3). Among 21 studies, eight studies were about "Mental and behavioural disorders (F00-99)". There were two studies in "Diseases of the nervous system (G00-99)" and "Diseases of the respiratory system (J00-99)", and one study in "Endocrine, nutritional and metabolic diseases (E00-90)", "Diseases of the circulatory system (I00-99)", and
"Pregnancy, childbirth and the puerperium (O60)". Because there were a variety of target diseases, there were six articles in which we could not identify a single disease.

\section{Evidence of effectiveness}

Table 4 presents a brief summary of 21 SRs. Five studies (ie, schizophrenia for global and mental state and social functioning, ${ }^{18}$ Parkinson's disease for gait and related activities, ${ }^{29}$ depressive symptoms, ${ }^{32}$ sleep quality, ${ }^{36}$ and serious mental disorders for global and social functioning ${ }^{37}$ ) concluded that there are effects of the intervention.

Ten studies with a meta-analysis (ie, cancer for anxiety, pain, mood, and QoL, ${ }^{19}$ advanced life-limiting illness for QoL, ${ }^{20}$ mechanically ventilated patients for heart rate, respiratory rate, and anxiety, ${ }^{22}$ multiple pain for intensity level and opioid requirement, ${ }^{23}$ acquired brain injury for gait parameters, ${ }^{24}$ autistic spectrum disorders for communicative skills, ${ }^{25}$ cesarean section for heart rate and birth satisfaction, ${ }^{26}$ coronary heart disease for blood pressure,

Table 3 International classification of target diseases in each article

\begin{tabular}{|c|c|c|c|}
\hline Chapter & ICD code & Classification & Study (detail ICD code) \\
\hline I & A00-B99 & Certain infectious and parasitic diseases & \\
\hline 2 & C00-D48 & Neoplasms & Bradt et al ${ }^{19}$ (unidentification about neoplasm type) \\
\hline 3 & D50-D89 & $\begin{array}{l}\text { Diseases of the blood and blood-forming organs and certain } \\
\text { disorders involving the immune mechanism }\end{array}$ & \\
\hline 4 & E00-E90 & Endocrine, nutritional and metabolic diseases & Irons et $\mathrm{al}^{34}$ (E84.9) \\
\hline 5 & F00-F99 & Mental and behavioral disorders & $\begin{array}{l}\text { Sinha et } \mathrm{al}^{17} \text { and Gold et } \mathrm{al}^{25} \text { (F84.0); Mossler et } \mathrm{al}^{18} \\
\text { (F2 I, F22); Vink et } \mathrm{al}^{2 \mathrm{I}} \text { (F00-03); Maratos et } \mathrm{al}^{28} \\
\text { (F30-33); Cogo-Moreira et } \mathrm{al}^{30} \text { (F8I.0); Chan et } \mathrm{al}^{32} \\
\text { (F30-33); and de Niet et } \mathrm{al}^{36} \text { (G47) }\end{array}$ \\
\hline 6 & G00-G99 & Diseases of the nervous system & Bradt et $\mathrm{al}^{24}(\mathrm{G} 46)$ and de Dreu et $\mathrm{al}^{29}(\mathrm{G} 20-2 \mathrm{I})$ \\
\hline 7 & $\mathrm{H} 00-\mathrm{H} 59$ & Diseases of the eye and adnexa & \\
\hline 8 & $\mathrm{H} 60-\mathrm{H} 95$ & Diseases of the ear and mastoid process & \\
\hline 9 & $100-199$ & Diseases of the circulatory system & Bradt and Dileo ${ }^{27}(120-25)$ \\
\hline 10 & J00-J99 & Diseases of the respiratory system & Bradt et $\mathrm{al}^{22}(\mathrm{~J} 44)$ and Irons et $\mathrm{al}^{35}(\mathrm{J47})$ \\
\hline II & K00-K93 & Diseases of the digestive system & \\
\hline 12 & L00-L99 & Diseases of the skin and subcutaneous tissue & \\
\hline 13 & M00-M99 & Diseases of the musculoskeletal system and connective tissue & \\
\hline 14 & N00-N99 & Diseases of the genitourinary system & \\
\hline 15 & O00-O99 & Pregnancy, childbirth and the puerperium & Laopaiboon et $\mathrm{al}^{26}(\mathrm{O} 60)$ \\
\hline 16 & P00-P96 & Certain conditions originating in the perinatal period & \\
\hline 17 & Q00-Q99 & $\begin{array}{l}\text { Congenital malformations, deformations and chromosomal } \\
\text { abnormalities }\end{array}$ & \\
\hline 18 & R00-R99 & $\begin{array}{l}\text { Symptoms, signs and abnormal clinical and laboratory } \\
\text { finding not elsewhere classified }\end{array}$ & \\
\hline 19 & S00-T98 & $\begin{array}{l}\text { Injury, positioning and certain other consequences } \\
\text { of external causes }\end{array}$ & \\
\hline 20 & V00-Y98 & External causes of morbidity and mortality & \\
\hline 21 & Z00-Z99 & Factors influencing health status and contact with health services & \\
\hline 22 & U00-U99 & Code for special purpose & \\
\hline- & Unidentification & Because many illnesses were mixed, we could not identify it & $\begin{array}{l}\text { Bradt and Dileo, }{ }^{20} \text { Cepeda et al, }{ }^{23} \text { Drahota et al, }{ }^{31} \\
\text { Naylor et } a l,{ }^{33} \text { and Gold et al }{ }^{37}\end{array}$ \\
\hline
\end{tabular}

Abbreviation: ICD, International Classification of Diseases. 


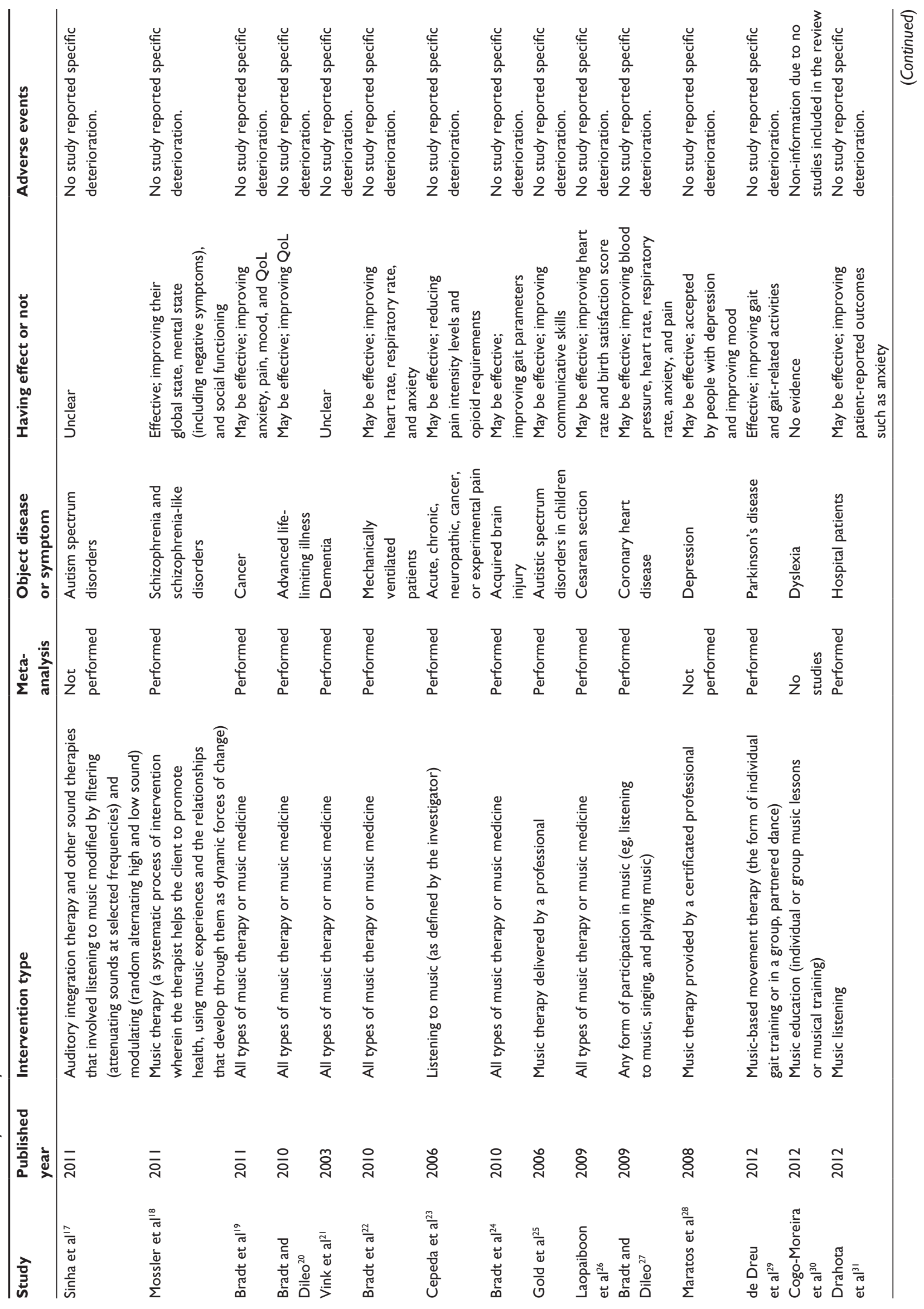




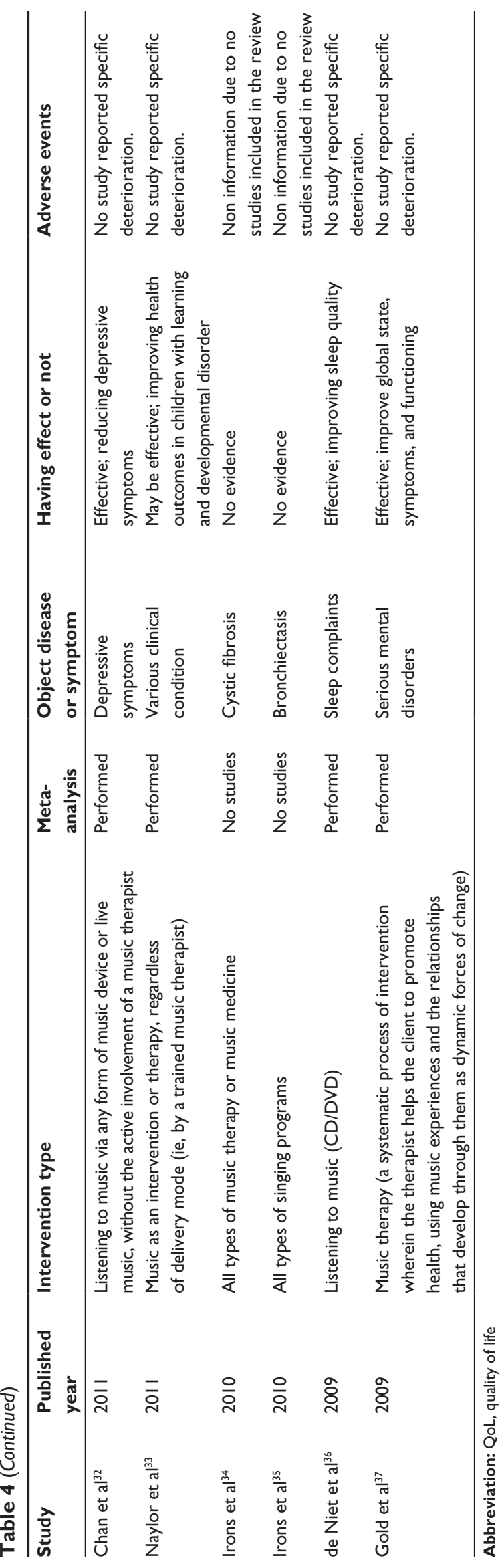

heart rate, respiratory rate, anxiety, and pain, ${ }^{27}$ hospital patients for self-reported outcomes such as anxiety, ${ }^{31}$ and various clinical conditions for health outcomes in children with learning and developmental disorder ${ }^{33}$ ) concluded that there might be an effect of the intervention. An SR without a meta-analysis of depression reported that there might be an effect of the intervention. ${ }^{28}$

Two studies (ie, autism spectrum ${ }^{17}$ and dementia ${ }^{21}$ ) described that the effect of intervention is unclear. There was no evidence for three studies (ie, dyslexia, ${ }^{30}$ cystic fibrosis, ${ }^{34}$ and bronchiectasis ${ }^{35}$ ) because they were not RCTs.

\section{Adverse events}

There were no specific adverse events in any of the studies.

\section{Quality assessment}

We evaluated eleven items from the AMSTAR checklist in more detail (Table 5). Inter-rater reliability metrics for the quality assessment indicated substantial agreement for all 231 items (percentage agreement $95.3 \%$ and $\kappa=0.825$ ). As a whole, the quality of the articles was very good.

\section{Discussion}

This is the first SR of SRs of the effectiveness of cure based on music interventions in studies with RCT designs. Our study is unique because it summarized the evidence for each target disease according to ICD-10 classification. We assume that this study will be helpful to researchers who want to grasp an effect of MT comprehensively and could provide information that is indispensable for the organization that is going to make the guidelines according to each disease.

Twenty-one SRs based on RCTs were identified, and music intervention was clearly effective for five diseases (ie, schizophrenia for global and mental state and social functioning, Parkinson's disease for gait and related activities, depressive symptoms, sleep quality, and serious mental disorders for global and social functioning).

A review of all SRs showed that there was no special adverse effect or harm associated with MT.

\section{Tendency of target disease and outcome}

The most commonly reported target diseases were "Mental and behavioural disorders (F00-99)", ${ }^{17,18,21,25,28,30,32,36}$ and the effect of MT on these diseases was improved mental health (eg, anxiety and mood), pain, QoL, and communication skills. The main reason given in these articles for improved mental health was that the beauty and rhythm of the music tone allowed the 
Table 5 AMSTAR is a measurement tool created to assess the methodological quality of systematic reviews

\begin{tabular}{|c|c|c|}
\hline & Total evaluation & $\mathbf{N}(\%)$ \\
\hline I. Was an "a priori" design provided? & $\square$ Yes & $20(95 \%)$ \\
\hline \multirow[t]{3}{*}{ The research question and inclusion criteria should be established before the conduct of the review. } & $\square$ No & $0(0 \%)$ \\
\hline & $\square$ Can't answer & I (5\%) \\
\hline & $\square$ Not applicable & $0(0 \%)$ \\
\hline 2. Was there duplicate study selection and data extraction? & $\square$ Yes & $21(100 \%)$ \\
\hline There should be at least two independent data extractors and a consensus procedure for disagreements & $\square$ No & $0(0 \%)$ \\
\hline \multirow[t]{2}{*}{ should be in place. } & $\square$ Can't answer & $0(0 \%)$ \\
\hline & $\square$ Not applicable & $0(0 \%)$ \\
\hline 3. Was a comprehensive literature search performed? & $\square$ Yes & $21(100 \%)$ \\
\hline At least two electronic sources should be searched. The report must include years and databases used & $\square$ No & $0(0 \%)$ \\
\hline (eg, CENTRAL, EMBASE, and MEDLINE). Keywords and/or MeSH terms must be stated and where feasible & $\square$ Can't answer & $0(0 \%)$ \\
\hline the search strategy should be provided. All searches should be supplemented by consulting current contents, & $\square$ Not applicable & $0(0 \%)$ \\
\hline
\end{tabular}
reviews, textbooks, specialized registers, or experts in the particular field of study, and by reviewing the references in the studies found.

4. Was the status of publication (ie, grey literature) used as an inclusion criterion?

The authors should state that they searched for reports regardless of their publication type.

The authors should state whether or not they excluded any reports (from the systematic review), based on their publication status, language etc.

5. Was a list of studies (included and excluded) provided?

A list of included and excluded studies should be provided.

6. Were the characteristics of the included studies provided?

In an aggregated form such as a table, data from the original studies should be provided on the participants, interventions and outcomes. The ranges of characteristics in all the studies analyzed, eg, age, race, sex, relevant socioeconomic data, disease status, duration, severity, or other diseases should be reported.

7. Was the scientific quality of the included studies assessed and documented?

"A priori" methods of assessment should be provided (eg, for effectiveness studies if the author(s)

chose to include only randomized, double-blind, placebo controlled studies, or allocation concealment as inclusion criteria); for other types of studies alternative items will be relevant.

8. Was the scientific quality of the included studies used appropriately in formulating conclusions?

The results of the methodological rigor and scientific quality should be considered in the analysis and the conclusions of the review, and explicitly stated in formulating recommendations.

9. Were the methods used to combine the findings of studies appropriate?

For the pooled results, a test should be done to ensure the studies were combinable, to assess their homogeneity (ie, chi-squared test for homogeneity, $\mathrm{I}^{2}$ ). If heterogeneity exists a random effects model should be used and/or the clinical appropriateness of combining should be taken into consideration (ie, is it sensible to combine?).

II. Was the conflict of interest stated?

Potential sources of support should be clearly acknowledged in both the systematic review

Abbreviations: CENTRAL, Cochrane Central Register of Controlled Trials; MeSH, Medical Subject Headings; Can't, can not.

patient to be comfortable. In studies about the effects of MT on anxiety, discomfort, fear, and pain, MT has been variably applied as an accessory treatment for persons with addictions, ${ }^{6}$ and as evasion of direct discomfort for undergoing medical device procedures such as colonoscopy ${ }^{8}{ }^{8}$ colposcopy ${ }^{9}$ and dental procedures. ${ }^{7}$
The second most frequently reported target diseases were "Diseases of the nervous system (G00-99)", 24,29 and the effects of MT on these diseases showed commonly gait parameters. MT is expected to improve gait and related activities such as rehabilitation in diseases of the central nervous system. There were also several 
studies that identified "Diseases of the respiratory system (J00-99)." 22,35 Improvements seen in these studies were mainly due to effects of singing on breathing function, such as respiratory rate, and on the circulation function, such as heart rate.

\section{Validity of overall evidence based on quality assessment}

We performed an evaluation of all SRs by the AMSTAR checklist developed to assess the methodological quality of SRs. There were no serious problems with the conduct and reporting of all target studies. This study included 16 Cochrane Reviews. ${ }^{17-28,30,31,34,35}$ In the Cochrane Reviews, the eligibility criteria for a meta-analysis are strict, and for each article, heterogeneity and low quality of reporting are to first be excluded. Therefore, we assumed that the conclusion of each SR had enough validity.

\section{Overall evidence}

Most importantly, a specific adverse effect or harmful phenomenon did not occur in any study, and MT was well tolerated by almost all patients. MT treatment has positive effects for the following: schizophrenia and/or serious mental disorders for global and social functioning, Parkinson's disease for gait and related activities, depressive symptoms, and sleep quality. We assume that the direct effects of MT are generally improvement of mental health and sense of rhythm, and reduction of pain. In addition, we assume that communication with other people improves through music, the sense of isolation disappears, and QoL rises.

Although further accumulation of RCT data is necessary, MT may be effective treatment for the following diseases and symptoms: cancer and/or advanced life-limiting illnesses affecting mental state and QoL, mechanically ventilated patients with impaired respiratory function and mental state, chronic pain requiring opioid treatment, acquired brain injury affecting gait parameters, autistic spectrum disorders involving communicative skills, cesarean section effects on heart rate and birth satisfaction, coronary heart disease effects on circulatory, respiratory function, and mental state, and self-reported outcomes for hospitalized patients and other patients with various clinical conditions. These SRs describe the need for additional high quality RCTs to assess the effect of MT.

\section{Future research agenda to build evidence}

Table 6 shows the future research agenda for studies on the treatment effect of MT. Because only SRs of RCTs were
Table 6 Future research agenda to build evidence of music therapy

\section{Item}

I. Long-term effect

2. Consensus of the intervention framework such as type, frequency, time for each disease*

3. Dose-response relationship

4. Description of cost

5. Development of the original checklist for music therapy**

Notes: *Reporting guidelines for intervention on each disease; **reporting guideline for research methodology on study plan, implementation, and description.

included in this study, their characteristic study designs limited our results to the assessment of short-term effects. Even if a study is not an RCT design, it is necessary to evaluate the long-term effects.

Because studies of intervention using music vary in design, a consensus of the framework is necessary. ${ }^{10}$ In this study, examination according to a detailed intervention method was not possible, but it would be important for future studies to define MT. Furthermore, studies to assess dose-response relationships according to each disease are clearly necessary. ${ }^{18}$

Bowen et $\mathrm{al}^{38}$ suggested that public health is moving toward the goal of implementing evidence-based intervention. However, the feasibility of possible interventions and whether comprehensive and multilevel evaluations are needed to justify them must be determined. It is at least necessary to show the cost of such interventions. We must introduce an interventional method based on its cost-benefit, cost-effectiveness, and cost-utility.

In addition, MT as an intervention is unique and completely different than pharmacological or traditional rehabilitation methods. Therefore, it may be necessary to add some original items like herbal intervention, ${ }^{39}$ aquatic exercise, ${ }^{40}$ and balneotherapy ${ }^{41}$ to the CONSORT 2010 checklist as alternative or complementary medicines.

\section{Strength and limitations}

This review has several strengths: 1) the methods and implementation registered high on the PROSPERO database; 2) it was a comprehensive search strategy across multiple databases with no data restrictions; 3 ) there were high agreement levels for quality assessment of articles; and 4) it involved detailed data extraction to allow for collecting all articles' content into a recommended structured abstract.

This review also had several limitations that should be acknowledged. Firstly, some selection criteria were common across studies, as described above; however, bias 
remained due to differences in eligibility for participation in each original RCT. Secondly, publication bias was a limitation. Although there was no linguistic restriction in the eligibility criteria, we searched studies with only English and Japanese keywords. Thirdly, in order to be specific to SRs based on RCTs, it ignores some excellent results of primary research by other research designs. Fourthly, as a point of terminology for MT, because we applied a broad definition to the use of music in medicine, it may be more confusing or a bit misleading in the cultural context of Western health care.

In addition, since this review focused on summaries of effects of MT for each disease, we did not describe all details on quality and quantity such as type of MT, frequency of MT, and time on MT. Moreover, we could not follow standard procedures as estimates of the effects of moderating variables. Finally, because we broadly defined MT as music appreciation, musical instrument performance, and singing, we could not assess a specific intervention.

\section{Conclusion}

This comprehensive summary of SRs demonstrates that MT treatment improved the following: global and social functioning in schizophrenia and/or serious mental disorders, gait and related activities in Parkinson's disease, depressive symptoms, and sleep quality. MT may have the potential for improving other diseases, but there is not enough evidence at present. Most importantly, a specific adverse effect or harmful phenomenon did not occur in any of the studies, and MT was well tolerated by almost all patients.

To most effectively assess the potential benefits of MT, it will be important for future research to explore 1) longterm effects, 2) a consensus of the framework of music intervention, 3) dose-response relationships, 4) the cost of the intervention, and 5) development of the original check item in MT.

\section{Acknowledgments}

We would like to express our appreciation to Ms Aya Maruyama (methodology of MT), Ms Rie Higashino, Ms Yoko Ikezaki, Ms Rinako Kai (paperwork), and Ms Satoko Sayama and Ms Mari Makishi (all searches of studies) for their assistance in this study.

\section{Author contributions}

All authors made substantial contributions to conception and design, acquisition of data, or analysis and interpretation of data. All authors took part in drafting the article or revising it critically for important intellectual content.

\section{Ethical approval}

No ethical approval was required.

\section{Data sharing}

No additional data are available.

\section{Funding}

This study was supported by the Health and Labour Sciences Research Grants (Research on Health Security Control ID No H24-021; representative Dr K Tsutani) from the Japanese Ministry of Health, Labour and Welfare of Japan in 2012 .

\section{Disclosure}

The authors report no conflicts of interest in this work.

\section{References}

1. Ostermann T, Schmid W. Music therapy in the treatment of multiple sclerosis: a comprehensive literature review. Expert Rev Neurother. 2006;6:469-477.

2. Gold C, Voracek M, Wigram T. Effects of music therapy for children and adolescents with psychopathology: a meta-analysis. J Child Psychol Psychiatry. 2004;45:1054-1063.

3. Hurkmans J, de Bruijn M, Boonstra AM, et al. Music in the treatment of neurological language and speech disorder: a systematic review. Aphasiology. 2012;26:1-19.

4. Standley J. Music therapy research in the NICU: an updated metaanalysis. Neonatal Network. 2012;31:311-316.

5. Nilsson U. The anxiety- and pain-reducing effects of music interventions: a systematic review. AORN J. 2008;87:780-807.

6. Mays KL, Clark DL, Gordon AJ. Treating addiction with tunes: a systematic review of music therapy for the treatment of patients with addictions. Substance Abuse. 2008;29:51-59.

7. Klassen JA, Liang Y, Tjosvold L, Klassen TP, Hartling L. Music for pain and anxiety in children undergoing medical procedures: a systematic review of randomized controlled trials. Ambul Pediatr. 2008;8: $117-128$.

8. Tam WWS, Wong ELY, Twinn SF. Effect of music on procedure time and sedation during colonoscopy: a meta-analysis. World $J$ Gastroenterol. 2008;14:5336-5343.

9. Galaal K, Bryant A, Deane KH, Al-Khaduri M, Lopes AD. Interventions for reducing anxiety in women undergoing colposcopy. Cochrane Database Syst Rev. 2011;(12):CD006013.

10. Dileo C. Effects of music and music therapy on medical patients: a meta-analysis of the research and implications for the future. $J$ Soc Integr Oncol. 2006;4:67-70.

11. Shea BJ, Grimshaw JM, Wells GA, et al. Development of AMSTAR: a measurement tool to assess the methodological quality of systematic reviews. BMC Med Res Methodol. 2007;7:10.

12. Hopewell S, Clarke M, Moher D, et al. CONSORT for reporting randomized trials in journal and conference abstracts. Lancet. 2008;371: 281-283.

13. Hopewell S, Ravaud P, Baron G, et al. Effect of editors' implementation of CONSORT guidelines on the reporting of abstracts in high impact medical journals: interrupted time series analysis. BMJ. 2012;344: e4178. 
14. Atkins D, Best D, Briss PA, et al. Grading quality of evidence and strength of recommendations. BMJ. 2004;328:1490-1497.

15. International Prospective Register of Systematic Reviews [database on the Internet]. York, UK: University of York. Available from: http://www. crd.york.ac.uk/prospero. Accessed June 20, 2012.

16. Booth A, Clarke M, Ghersi D, et al. An international registry of systematic review protocols. Lancet. 2011;377:108-109.

17. Sinha Y, Silove N, Hayen A, Williams K. Auditory integration training and other sound therapies for autism spectrum disorders (ASD). Cochrane Database Syst Rev. 2011;12:CD003681.

18. Mossler K, Chen X, Heldal TO, et al. Music therapy for people with schizophrenia and schizophrenia-like disorders. Cochrane Database Syst Rev. 2011;12:CD004025.

19. Bradt J, Dileo C, Grocke D, et al. Music interventions for autistic spectrum disorder. Cochrane Database Syst Rev. 2011;8:CD006911.

20. Bradt J, Dileo C. Music therapy for end-of-life care. Cochrane Database Syst Rev. 2010;1:CD007169.

21. Vink AC, Birks JS, Bruinsma MS, Scholten RJ. Music therapy for people with dementia. Cochrane Database Syst Rev. 2003;4: CD003477.

22. Bradt J, Dileo C, Grocke D. Music interventions for mechanically ventilated patients. Cochrane Database Syst Rev. 2010;12:CD006902.

23. Cepeda MS, Carr DB, Lau J, et al. Music for pain relief. Cochrane Database Syst Rev. 2006;2:CD004843.

24. Bradt J, Magee WL, Dileo C, et al. Music interventions for acquired brain injury. Cochrane Database Syst Rev. 2010;7:CD006787.

25. Gold C, Wigram T, Elefant C. Music therapy for autistic spectrum disorder. Cochrane Database Syst Rev. 2006;2:CD004381.

26. Laopaiboon M, Lumbiganon P, Martis R, et al. Music during caesarean section under regional anaesthesia for improving maternal and infant outcomes. Cochrane Database Syst Rev. 2009;2:CD006914.

27. Bradt J, Dileo C. Music for stress and anxiety reduction in coronary heart disease patients. Cochrane Database Syst Rev. 2009;2: CD006577.

28. Maratos A, Gold C, Wang X, et al. Music therapy for depression. Cochrane Database Syst Rev. 2008;1:CD004517.

29. de Dreu MJ, van der Wilk AS, Poppe E, Kwakkel G, van Wegen EE. Rehabilitation, exercise therapy and music in patients with Parkinson's diseases: a meta-analysis of the effects of music-based movement therapy on walking ability, balance and quality of life. Parkinsonism Relat Disord. 2012;18 Suppl 1:S114-S119.
30. Cogo-Moreira H, Andriolo RB, Yazigi L, et al. Music education for improving reading skills in children and adolescents with dyslexia. Cochrane Database Syst Rev. 2012;8:CD009133.

31. Drahota A, Ward D, Mackenzie H, et al. Sensory environment on health-related outcomes of hospital patients. Cochrane Database Syst Rev. 2012;3:CD005315.

32. Chan MF, Wong ZY, Thayala NV. The effectiveness of music listening in reducing depressive symptoms in adults: a systematic review. Complement Ther Med. 2011;19:332-348.

33. Naylor KT, Kingsnorth S, Lamont A, et al. The effectiveness of music in pediatric healthcare: a systematic review of randomized controlled trials. Evid Based Complement Alternat Med. 2011;2011:464759.

34. Irons JY, Kenny DT, Chang AB. Singing for children and adults with cystic fibrosis. Cochrane Database Syst Rev. 2010;5:CD008036.

35. Irons JY, Kenny DT, Chang AB. Singing for children and adults with bronchiectasis. Cochrane Database Syst Rev. 2010;2:CD007729.

36. de Niet G, Tiemens B, Lendemeijer B, Hutschemaekers G. Musicassisted relaxation to improve sleep quality: meta-analysis. J Adv Nurs. 2009;65:1356-1364.

37. Gold C, Solli HP, Kruger V, et al. Dose-response relationship in music therapy for people with serious mental disorders: systematic review and meta-analysis. Clin Psychol Rev. 2009;29:193-207.

38. Bowen DJ, Kreuter M, Spring B, et al. How we design feasibility studies. Am J Prev Med. 2009;36:452-457.

39. Gragnier JJ, Boon H, Rochon P, et al. Reporting randomized, controlled trials of herbal interventions: an elaborated CONSORT statement. Ann Intern Med. 2006;144:364-367.

40. Kamioka H, Tsutani K, Okuizumi H, et al. Effectiveness of aquatic exercise and balneotherapy: a summary of systematic reviews based on randomized controlled trials of water immersion therapies. J Epidemiol. 2010;20:2-12.

41. Kamioka K, Kawamura Y, Tsutani $\mathrm{K}$ et al. A checklist to assess the quality of reports on spa therapy and balneotherapy trials was developed using the Delphi consensus method: the SPAC checklist. Complement Ther Med. 2013;21(4):324-332. 


\section{Supplementary material}

Table SI References to studies excluded in this review

\begin{tabular}{ll}
\hline First author. Journal (Year) & Title \\
\hline Standley J. Neonatal Netw (20I2) & $\begin{array}{l}\text { Music therapy research in the NICU: an updated meta-analysis } \\
\text { Wittwer JE. Disabil Rehabil (20I2) }\end{array}$ \\
$\begin{array}{l}\text { Rhythmic auditory cueing to improve walking in patients with neurological } \\
\text { conditions other than Parkinson's disease - what is the evidence? }\end{array}$ \\
Hurkmans J. Aphasiology (2012) & $\begin{array}{l}\text { Music in the treatment of neurological language and speech disorders: } \\
\text { a systematic review }\end{array}$ \\
Burns DS. J Music Ther (20I2) & $\begin{array}{l}\text { Theoretical rationale for music selection in oncology intervention } \\
\text { research: an integrative review }\end{array}$ \\
Fredericks S. Clin Nurs Res (2012) & $\begin{array}{l}\text { Anxiety, depression, and self-management: a systematic review } \\
\text { Interventions for reducing anxiety in women undergoing colposcopy }\end{array}$
\end{tabular}

Syst Rev (20II)

Pittman S. Int Nurs Rev (20II)

Cogo-Moreia H. Cochrane

Database Syst Rev (20II)

Schmid W. BMC Health Serv

Res (2010)

Renner RM. Contraception (2010)

de Niet GJ. Int J Evid Based

Healthc (2009)

Engwall M. J Perianesth Nurs (2009)

Harting L. Arch Dis Child

Fetal Neonatal Ed (2009)

Bechtold ML. Dig Dis Sci (2009)

Klassen JA. Ambul Pediatr (2008)

Tam WW. World J Gastroenterol (2008)

Gillen E. Int J Evid Based

Healthc (2008)

Dileo C. Cochrane Database

Syst Rev (2008)

Mays KL. Subst Abus (2008)

Music intervention and preoperative anxiety: an integrative review

Music education for improving reading skills in children

and adolescents with dyslexia

Home-based music therapy - a systematic overview

of settings and conditions for an innovative service in healthcare

Pain control in first-trimester surgical abortion:

Reason for exclusion

Not SR based on RCTs

Not SR based on RCTs

Not SR based on RCTs

Not SR based on RCTs

Not SR based on RCTs

Not treatment or

rehabilitation

Not SR based on RCTs

Updated or

replacement $S R$

Not SR based on RCTs

a systematic review of randomized controlled trials

Review of systematic reviews about the efficacy of non-pharmacological

Not music therapy

interventions to improve sleep quality in insomnia

Music as a nursing intervention for postoperative pain:

a systematic review

Music for medical indications in the neonatal period:

a systematic review of randomised controlled trials

Effect of music on patients undergoing colonoscopy:

a meta-analysis of randomized controlled trials

Music for pain and anxiety in children undergoing medical

procedures: a systematic review of randomized controlled trials

Effect of music on procedure time and sedation during

colonoscopy: a meta-analysis

Effects of music listening on adult patients' pre-procedural

state anxiety in hospital

Music for preoperative anxiety

Treating addiction with tunes: a systematic review of music

therapy for the treatment of patients with addictions

Music for pain and anxiety in children undergoing medical

procedures: a systematic review of randomized controlled trials

Interventions for reducing anxiety in women undergoing colposcopy

Galaal K. Cochrane Database

Syst Rev (2007)

Rudin D. Endoscopy (2007)

Richards T. Medsurg Nurs (2007)

Vanderboom T. J Radiol Nurs (2007)

Lim PH. Int Nurs Rev (2006)

Ostermann T. Expert Rev

Neurother (2006)

Dileo C. J Soc Integr Oncol (2006)

Sung HC. J Clin Nurs (2005)

Music in the endoscopy suite: a meta-analysis of randomized controlled studies

The effect of music therapy on patients' perception and manifestation

of pain, anxiety, and patient satisfaction

Does music reduce anxiety during invasive procedures with procedural sedation? An integrative research review

Music as nursing intervention for pain in five Asian countries

Music therapy in the treatment of multiple sclerosis:

a comprehensive literature review

Effects of music and music therapy on medical patients:

Not music therapy

Not treatment or

rehabilitation

Not treatment or

rehabilitation

Not treatment or

rehabilitation

Not treatment or

rehabilitation

Not treatment or

rehabilitation

Not treatment or

rehabilitation

Protocol

Not SR based on RCTs

Not treatment or

rehabilitation

Not treatment or

rehabilitation

Not treatment or

rehabilitation

Not SR based on RCTs

Not SR based on RCTs

Not SR based on RCTs

Not SR based on RCTs

Not SR based on RCTs

a meta-analysis of the research and implications for the future

Use of preferred music to decrease agitated behaviors

in older people with dementia: a review of the literature

Not SR based on RCTs

(Continued) 
Table SI (Continued)

\begin{tabular}{|c|c|c|}
\hline First author. Journal (Year) & Title & Reason for exclusion \\
\hline Pelletier CL. J Music Ther (2004) & The effect of music on decreasing arousal due to stress: a meta-analysis & Not SR based on RCTs \\
\hline Whipple J. J Music Ther (2004) & $\begin{array}{l}\text { Music in intervention for children and adolescents with autism: } \\
\text { a meta-analysis }\end{array}$ & Not SR based on RCTs \\
\hline Wilkins MK. Evid Based Nurs (2004) & $\begin{array}{l}\text { Music intervention in the intensive care unit: a complementary } \\
\text { therapy to improve patient outcomes }\end{array}$ & Not SR based on RCTs \\
\hline Gold C. J Child Psychol Psychiatry (2004) & $\begin{array}{l}\text { Effects of music therapy for children and adolescents } \\
\text { with psychopathology: a meta-analysis }\end{array}$ & Not SR based on RCTs \\
\hline Silverman MJ.J Music Ther (2003) & The influence of music on the symptoms of psychosis: a meta-analysis & $\begin{array}{l}\text { Not treatment or } \\
\text { rehabilitation }\end{array}$ \\
\hline Standley JM. J Pediatr Nurs (2002) & A meta-analysis of the efficacy of music therapy for premature infants & Not SR based on RCTs \\
\hline Evans D. J Adv Nurs (2002) & $\begin{array}{l}\text { The effectiveness of music as an intervention for hospital patients: } \\
\text { a systematic review }\end{array}$ & Not SR based on RCTs \\
\hline $\begin{array}{l}\text { You ZY. Acta Academiae } \\
\text { Med Sinicae (2002) }\end{array}$ & Meta-analysis of assisted music therapy for chronic schizophrenia & $\begin{array}{l}\text { Reduplication study/ } \\
\text { error of selection }\end{array}$ \\
\hline $\begin{array}{l}\text { You ZY. Zhongguo Yi Xue Ke } \\
\text { Xue Yuan Xue Bao (2002) }\end{array}$ & Meta-analysis of assisted music therapy for chronic schizophrenia & $\begin{array}{l}\text { Updated or } \\
\text { replacement SR }\end{array}$ \\
\hline $\begin{array}{l}\text { Evans D. Joanna Briggs Institute Evidence } \\
\text { Based Nurs Midwifery (200I) }\end{array}$ & Music as an intervention for hospital patients: a systematic review & Not SR based on RCTs \\
\hline $\begin{array}{l}\text { Koger SM. Cochrane Database } \\
\text { Syst Rev (2000)* }\end{array}$ & Music therapy for dementia symptoms & $\begin{array}{l}\text { Updated or } \\
\text { replacement SR }\end{array}$ \\
\hline $\begin{array}{l}\text { Koger SM. Cochrane Database } \\
\text { Syst Rev }(2000)^{*}\end{array}$ & Music therapy for dementia symptoms & $\begin{array}{l}\text { Updated or } \\
\text { replacement SR }\end{array}$ \\
\hline Koger SM. J Music Ther (1999) & $\begin{array}{l}\text { Is music therapy an effective intervention for dementia? } \\
\text { A meta-analytic review of literature }\end{array}$ & Not SR based on RCTs \\
\hline
\end{tabular}

Note: *Published and reformed in the same year.

Abbreviations: NICU, neonatal intensive care unit; RCT, randomized controlled trial; SR, systematic review.

\section{Publish your work in this journal}

Patient Preference and Adherence is an international, peer-reviewed, open access journal focusing on the growing importance of patient preference and adherence throughout the therapeutic continuum. Patient satisfaction, acceptability, quality of life, compliance, persistence and their role in developing new therapeutic modalities and compounds to optimize clinical outcomes for existing disease states are major areas of interest. This journal has been accepted for indexing on PubMed Central. The manuscript management system is completely online and includes a very quick and fair peer-review system. Visit http://www.dovepress.com/ testimonials.php to read real quotes from published authors. 